\title{
MODIFICACIONES CLIMÁTICAS Y EVOLUCIÓN DE LA CUBIERTA VEGETAL EN LAS ÁREAS CULMINANTES DE LA SIERRA DE GUADARRAMA (SISTEMA CENTRAL ESPAÑOL) DURANTE LA SEGUNDA MITAD DEL SIGLO XX: LAS ALTAS CUENCAS DEL VENTISQUERO DE LA CONDESA Y DE VALDEMARTÍN.
}

(1) Departamento de Análisis Geográfico Regional y Geografía Física. Facultad de Geografía e Historia. Universidad Complutense. Madrid (2) Instituto de Geografía. Universidad Nacional Autónoma de México. México D.F.

RESUMEN. Con el objeto de apreciar la relación entre las modificaciones climáticas recientes y los cambios apreciados en la cubierta vegetal de las áreas supraforestales del Sistema Central español se estudian dos pequeñas cuencas contiguas (La Condesa y Valdemartín) situadas en uno de los sectores más elevados de la Sierra de Guadarrama, muy cerca del Puerto de Navacerrada, donde existe un observatorio meteorológico perteneciente a la Red Principal que proporciona datos completos y fiables desde mediados del siglo XX. Se analiza mediante fotointerpretación la extensión de las seis facies principales que componen la vegetación dentro de las indicadas cuencas en los años 1957, 1972, 1984, 1991 y 1998 y se aprecia la correlación de los resultados obtenidos con la evolución de 18 parámetros climáticos a lo largo del período 1951-2000. El alto valor de los índices obtenidos y la básica analogía de las líneas de tendencia permite constatar que las dimensiones del área de las facies vegetales se ha modificado siguiendo el sentido y el ritmo de los cambios de los parámetros referentes a la temperatura y a la duración de la nieve. Se concluye así que la cubierta vegetal ha sido sensible a las variaciones climáticas acaecidas en el período analizado y ha respondido a ella reduciendo la extensión de los ventisqueros, de los pastizales higrófilos y de los matorrales abiertos y ampliando el área de los pastizales psicroxerófilos y de los matorrales densos.

ABSTRACT. The purpose of this study was to determine the relationship between recent climate changes and observed changes in the plant cover in the supraforest areas of the Central Mountain Range in Spain. Two small adjacent basins (La Condesa and Valdemartin) were selected as research sites at 
high altitude near a long-established national weather station at Puerto de Navacerrada in Sierra de Guadarrama. Aerial photograph interpretation was used to detect changes in vegetation at the sites in 1957, 1972, 1984, 1991 and 1998, and the results showed a correlation among the 18 climate-related parameters for the period 1951-2000. High index values and a basic similarity in tendencies confirmed that the extension of the plant facies had changed in accordance with variations in temperature and snow cover. As are result, it was determined that plant cover was sensitive to climate changes that had occurred during the study period and had responded by reducing the extent of the snowfields, hydrophytic meadows and open scrublands while expanding the pychroxerophytic meadows and dense scrublands.

Palabras clave: Cambios climáticos, vegetación supraforestal, nieve, Sierra de Guadarrama.

Key words: Climate changes, supraforest vegetation, snow, Sierra de Guadarrama.

Enviado en Junio de 2004

Aceptado en Septiembre de 2004

\section{Introducción: objetivos y metodología}

La interpretación de las fotografías aéreas que se han venido realizando entre los años 1957 y 2000 permite observar cómo en las cuencas del Ventisquero de La Condesa y de Valdemartín, situadas a más de 1800 m de altura en el sector central de la Sierra de Guadarrama donde tiene su cabecera el río Manzanares (Fig. 1), se han producido algunos cambios significativos en la distribución y las dimensiones relativas de las formaciones que constituyen su cubierta vegetal, destacando entre ellos los que afectan a los herbazales muy abiertos de especies adaptadas a una alta duración de la cubierta nival (formaciones quionófilas de ventisquero), a los pastizales psicroxerófilos ("joragales"), a los pastizales higrófilos ("cervunales") y a los matorrales de leguminosas ("piornales”). El análisis de los datos proporcionados en el período 1951-2000 por la estación de observación meteorológica del Puerto de Navacerrada (1889 m de altura), perteneciente a la Red Principal y emplazada a muy poca distancia $(2 \mathrm{~km})$ de las indicadas cuencas, pone de manifiesto igualmente cómo a lo largo de la segunda mitad del siglo XX se han producido modificaciones apreciables en varios parámetros meteorológicos anuales y estacionales, entre los que se encuentran los referentes al nivel termométrico y a la duración de la cubierta nival.

Para establecer y valorar la relación que pueda existir entre estas modificaciones del ambiente atmosférico y la evolución superficial de la cubierta vegetal se ha realizado, mediante trabajo de campo, la definición de las 6 facies básicas que la componen y se ha cartografiado y medido el área de cada una de ellas en las imágenes fotográficas correspondientes a cinco vuelos sucesivos. Por su parte, los datos referentes a 18 parámetros climáticos en el período de referencia han sido sometidos a un completo análisis estadístico tendente a definir de forma precisa el valor y el sentido de sus modificaciones, así como la configuración de sus líneas de tendencia. Partiendo de la hipótesis de que la distribución de los elementos de la cubierta vegetal en un ámbito supraforestal 


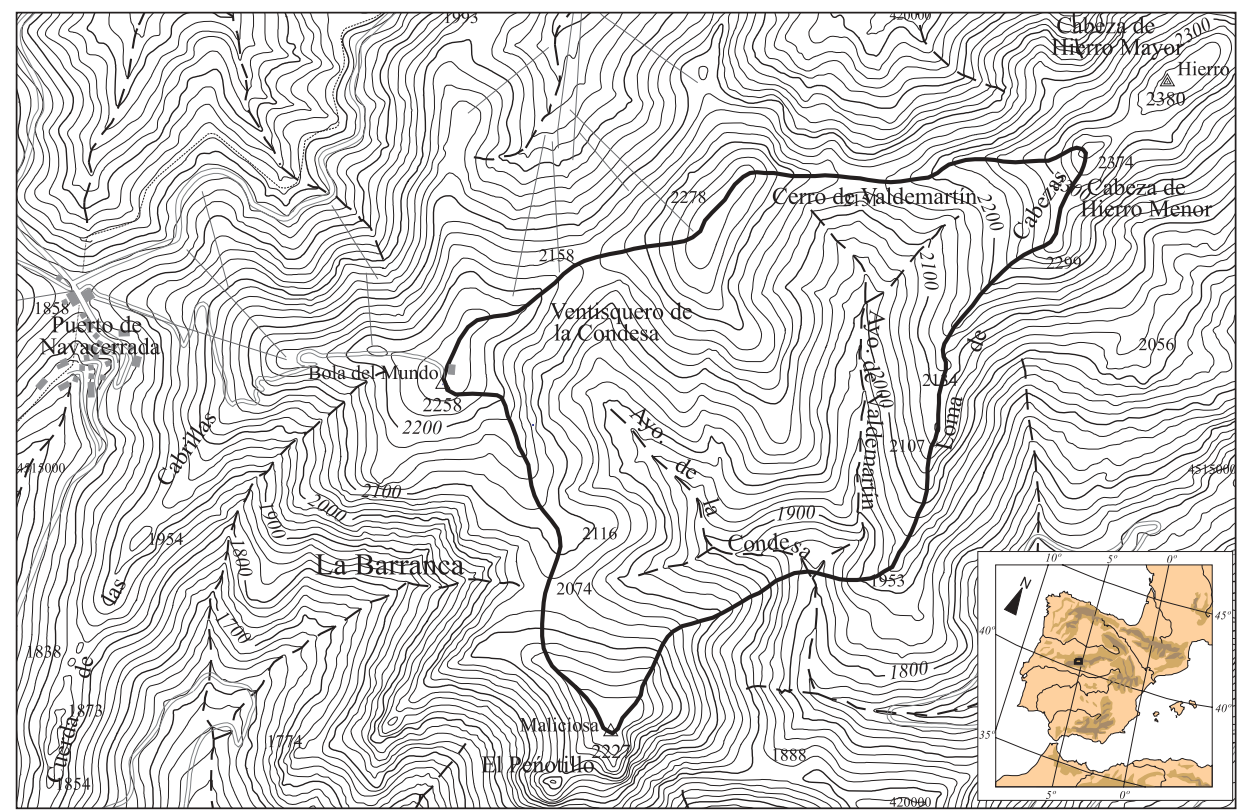

Figura 1. Localización y emplazamiento de las cuencas de La Condesa y Valdemartín dentro de la sierra de Guadarrama.

de alta montaña han de reflejar en mayor o menor medida las condiciones climáticas reinantes en los años inmediatamente anteriores, el indicado período se ha dividido en cinco intervalos o "tramos" delimitados por las fechas de realización de los vuelos utilizados y se han obtenido los valores medios de los parámetros climáticos en cada uno de ellos. El cálculo y análisis de los índices de correlación entre estos valores medios de tramo con las superficies ocupadas por los componentes de la cubierta vegetal al final de cada uno de ellos, junto con la apreciación de las analogías entre líneas de tendencia de éstas y aquéllos, ha permitido definir y cuantificar las relaciones de las modificaciones recientes del clima con los cambios en el paisaje vegetal del área estudiada.

Se han interpretado, en concreto, las fotografías aéreas correspondientes a los vuelos efectuados en 1957, 1972, 1984, 1991 y 1998 y para la localización, la cartografía y la medida de los recintos definidos se ha usado el Sistema de Información Geográfica ILWIS 3.0, utilizando como apoyo una Ortofoto Digital de 1998 (Fig. 2). Una vez interpretados, los fotogramas han sido convertidos a formato digital e incorporados al indicado SIG, mediante lo cual han sido corregidos geométricamente y georreferenciados de forma precisa; las bases de datos así generadas para todas y cada una de las cinco coberturas de fotografía aérea indicadas han sido exportadas a un programa estadístico, gracias al cual se han hallado las superficies y porcentajes correspondientes a las distintas coberturas vegetales, así como los índices de cambio entre las distintas fechas. Por su parte, la información climática procede de un estudio detallado sobre la Climatología de 


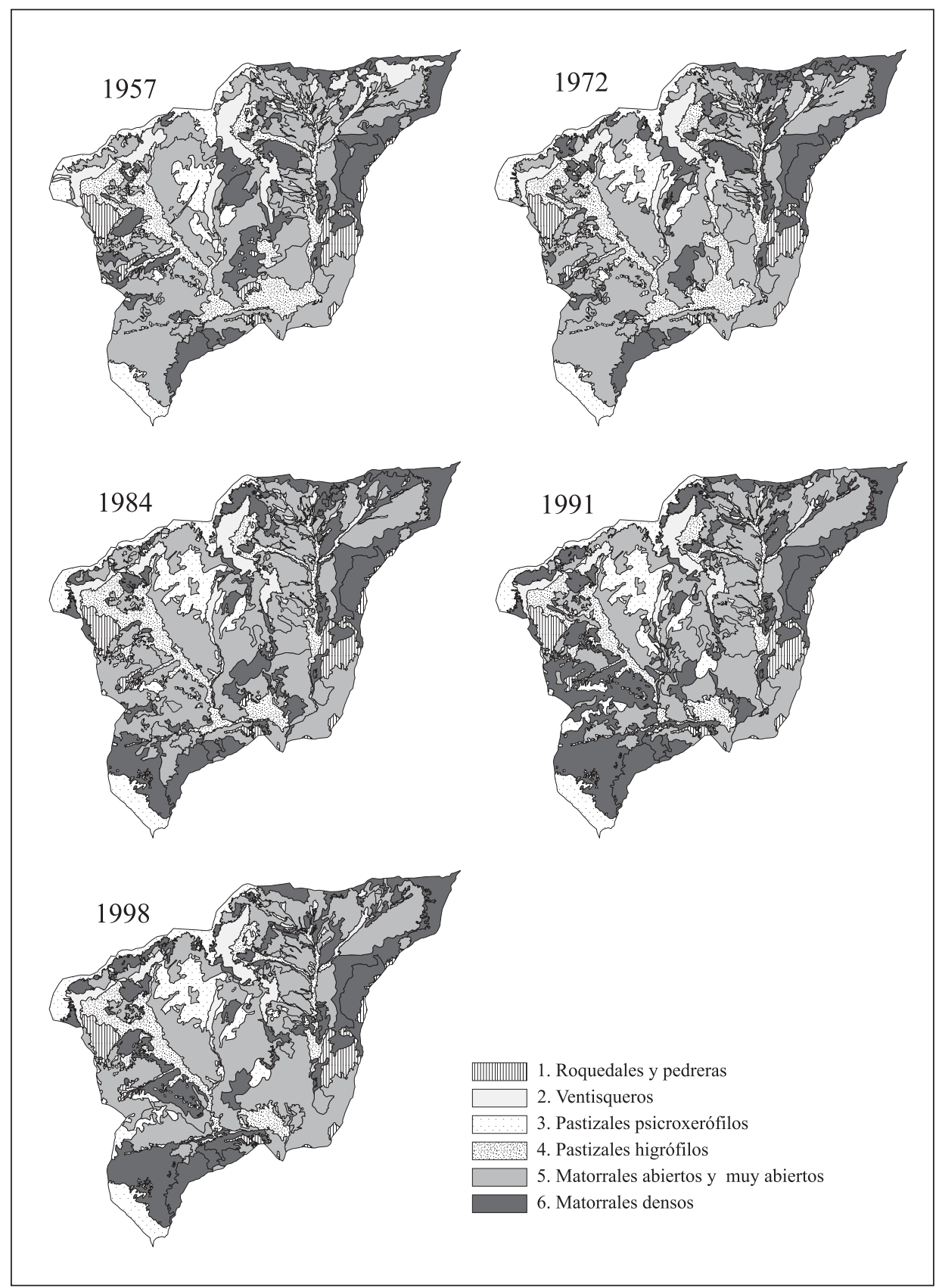

Figura 2. Distribución superficial de las facies básicas de paisaje vegetal en las cuencas de La Condesa y Valdemartín resultante de la interpretación de las imágenes aéreas de 1957, 1972, 1984, 1991 y 1998. 
Puerto de Navacerrada, que recoge los registros correspondientes al período 1951-1983 (Alarcón López et al., 1984), y de los Valores normales y estadísticos de este observatorio publicados por el Instituto Nacional de Meteorología con referencia a los períodos 1961-1990 y 1971-2000 (Instituto Nacional de Meteorología, 1995 y 2002). Para analizar las tendencias se ha utilizado líneas polinómicas y para valorar la correlación entre parámetros climáticos y áreas de vegetación se ha usado el Indice de correlación de Pearson.

\section{Caracterización y encuadre del área de estudio}

El territorio estudiado, cuya extensión total apenas sobrepasa las 550 ha, corresponde, como se ha dicho, a las cuencas contiguas de dos pequeños cursos torrenciales de la vertiente meridional de la sierra de Guadarrama -los arroyos de La Condesa y de Valdemartín (Fotos 1 y 2)- que tienen su cabecera en el tramo más elevado de la Cuerda Larga, entre las cumbres de La Maliciosa (2227 m), la Bola del Mundo (2258 m), el cerro de Valdemartín (2278 m) y las Cabezas de Hierro (2374 m), y confluyen a $1820 \mathrm{~m}$ para dar lugar al río que poco después recibe ya el nombre de Manzanares. Vistas en conjunto estas cuencas, modeladas en su práctica totalidad sobre materiales neísicos, conforman una elevada concavidad de $2047 \mathrm{~m}$ de altura media cerrada al SE por el cordal de la Loma de las Cabezas (1953-2299 m) que marca la transición con los vigorosos relieves graníticos de La Pedriza (Sanz, 1988). Dentro del área culminante donde se ubica, la temperatura media anual es inferior a $\operatorname{los} 7,0^{\circ}$ y se reciben cada año por término medio $1365 \mathrm{~mm}$ de agua distribuidos en alrededor de 150 días de precipitación, produciéndose ésta en forma de nieve en la mitad de los casos; pero lo más importante es que, debido a que la temperatura media anual de las mínimas no sobrepasa los $3,0^{\circ}$ y las mínimas medias mensuales son negativas en al menos la mitad del año, la nieve puede mantenerse sobre el suelo durante más de 70 días por término medio y en algunos enclaves particularmente favorecidos por la altura, la orientación y la topografía su permanencia puede alcanzar en promedio los 200 días/año (Instituto Nacional de Meteorología, 2002).

En conformidad con estos parámetros climáticos la cubierta vegetal potencial no tiene carácter forestal y está constituida fundamentalmente por matorrales de piorno y o de piorno y enebro rastrero (Sanz, 1979; Gavilán, et al., 1998; Rivas-Martínez et al., 1999), que sólo en las cumbres es sustituida por pastizales psicroxerófilos y en los fondos húmedos por praderas higrófilas, siendo la vegetación muy escasa en los roquedales y en las pedreras (Rivas-Martínez et al., 1989). En las áreas particularmente favorables para la acumulación y la persistencia de la nieve (ventisqueros) la cubierta vegetal corresponde, por su parte, a laxas formaciones herbáceas con alta presencia de especies quionófilas (adaptadas a la presencia de un duradero y a veces voluminoso recubrimiento nival) (Palacios y García, 1997).

Desde el punto de vista administrativo, las cuencas de La Condesa y Valdemartín, quedan dentro del municipio madrileño de Manzanares el Real, perteneciendo a los terrenos de titularidad pública del mismo, y al igual que los espacios supraforestales que 


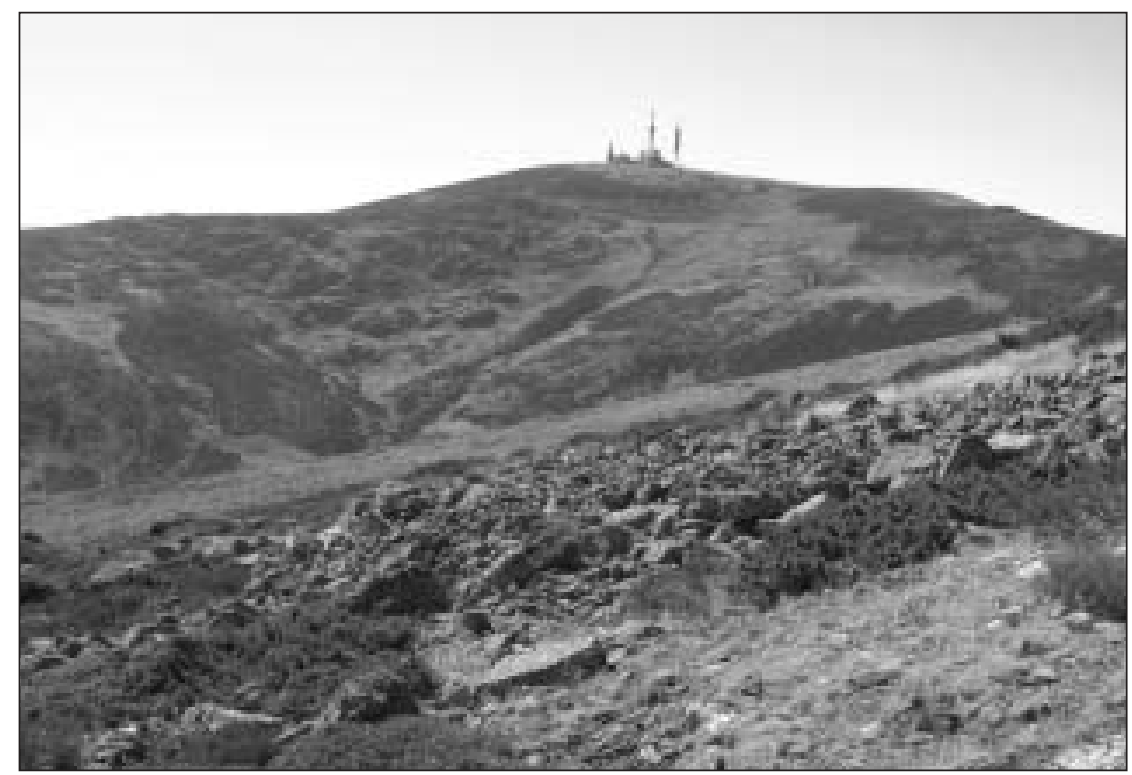

Foto 1. Cabecera de la cuenca de La Condesa.

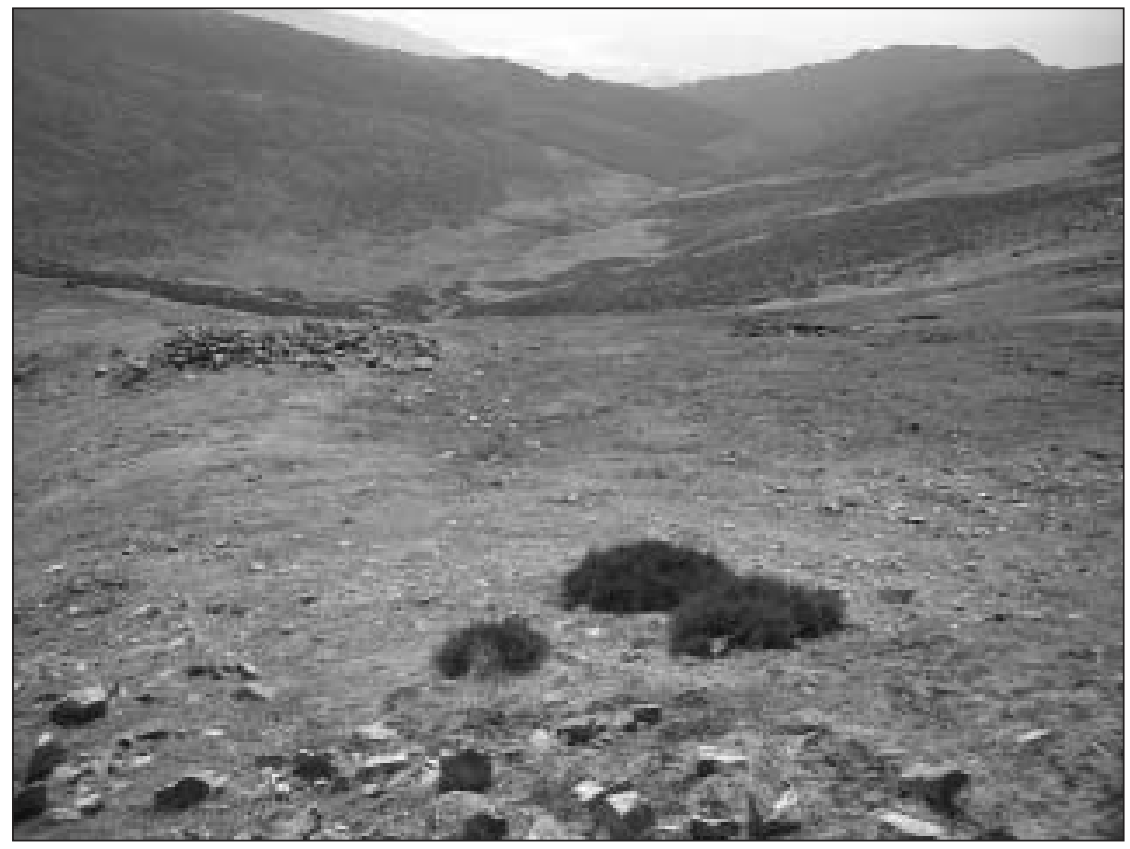

Foto 2. Fondo de la cuenca de La Condesa. 

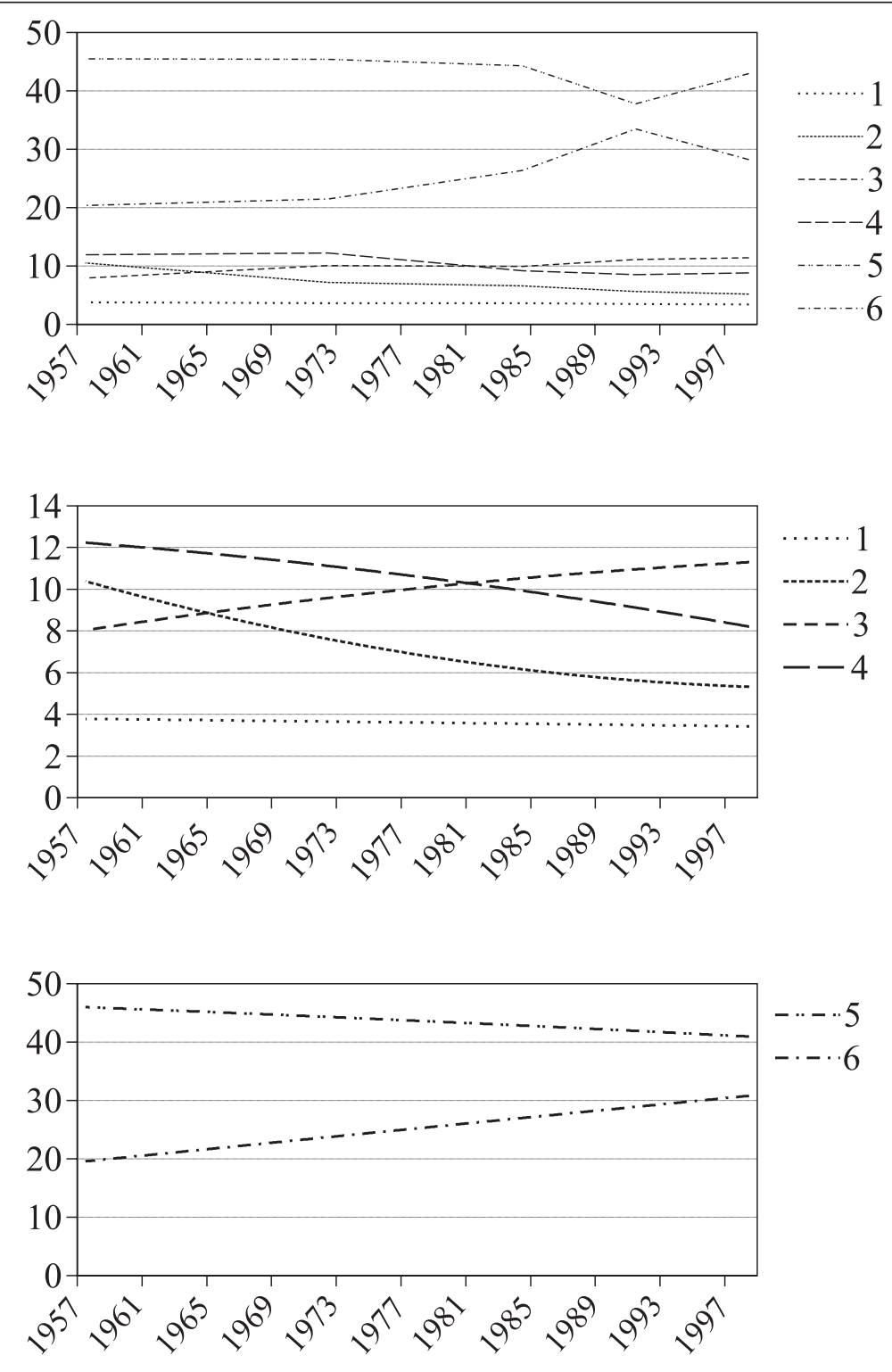

Figura 3. Evolución del porcentaje de la superficie de las cuencas de La Condesa y Valdemarín ocupado por las seis facies vegetales básicas a lo largo de la segunda mitad del siglo XX (Gráfico superior) y líneas polinómicas de tendencia correspondientes a cada una de ellas (Gráfico central e inferior). [1: Roquedales y pedreras. 2:

Ventisqueros. 3: Pastizales psicroxerófilos. 4:Pastizales higrófilos. 5: Matorrales abiertos y muy abiertos. 6: Matorrales densos]. 
las circundan han sido y son objeto de un aprovechamiento muy poco intenso y casi exclusivamente ganadero (Valenzuela Rubio, 1977; Mas, 1998). En ellas pastan unos pocos centenares de cabezas, muy mayoritariamente de vacuno en la actualidad, que se desplazan libremente por el área y tienden a concentrarse en los sectores donde predominan las formaciones herbáceas o donde los matorrales son más abiertos. Anteriormente, desde el siglo XVII hasta las primeras décadas del XX, esta actividad ganadera -que incluía la quema de piornales para incrementar el área de pastos- se ha combinado con la explotación de los ventisqueros, sobre todo del de La Condesa, para abastecer de nieve a las ciudades y "reales sitios" próximos (Madrid, Segovia, La Granja y el Escorial); dicha explotación, que incluía la construcción y el mantenimiento de muros en la parte baja de las áreas de mayor acumulación nival y su recubrimiento con paja u hojarasca para ralentizar la fusión de la nieve, está del todo ausente en el período analizado aunque se mantuvo con carácter residual hasta alrededor de 1930 (Corella, 1988).

\section{Definición de los grandes tipos o facies de paisaje vegetal y de su evolución superficial}

El reconocimiento del terreno con el apoyo de la Ortofoto digital de 1998 ha permitido diferenciar en el área hasta 14 unidades elementales de paisaje vegetal, las cuales, teniendo en cuenta sus caracteres genéricos y la composición de su cubierta vegetal, se han agrupado en los 6 grandes tipos que se describen a continuación y cuya evolución superficial -obtenida de la interpretación de las fotos aéreas de 1957, 1972, 1984, 1991 y 1998- igualmente se indica (Tabla 1).

Tabla 1. Superficie ocupada por las facies de vegetación en las fechas correspondientes a las coberturas de fotografía aérea utilizadas.

\begin{tabular}{|l|c|c|c|c|c|}
\hline & $\mathbf{1 9 5 7}$ & $\mathbf{1 9 7 2}$ & $\mathbf{1 9 8 4}$ & $\mathbf{1 9 9 1}$ & $\mathbf{1 9 9 8}$ \\
\hline 1. Roquedales y pedreras & $20,94 \mathrm{~h}$ & $\begin{array}{c}19,96 \mathrm{~h} \\
3,8 \%\end{array}$ & $\begin{array}{c}19,77 \mathrm{~h} \\
3,6 \%\end{array}$ & $\begin{array}{c}19,22 \mathrm{~h} \\
3,5 \%\end{array}$ & $\begin{array}{c}18,97 \mathrm{~h} \\
3,4 \%\end{array}$ \\
\hline 2. Ventisqueros & $\begin{array}{c}57,62 \mathrm{~h} \\
10,5 \%\end{array}$ & $\begin{array}{c}39,47 \mathrm{~h} \\
7,2 \%\end{array}$ & $\begin{array}{c}36,10 \mathrm{~h} \\
6,6 \%\end{array}$ & $\begin{array}{c}31,09 \mathrm{~h} \\
5,6 \%\end{array}$ & $\begin{array}{c}28,70 \mathrm{~h} \\
5,2 \%\end{array}$ \\
\hline 3. Pastizales psicroxerófilos & $43,82 \mathrm{~h}$ & $55,67 \mathrm{~h}$ & $54,46 \mathrm{~h}$ & $60,84 \mathrm{~h}$ & $62,58 \mathrm{~h}$ \\
& $7,9 \%$ & $10,1 \%$ & $9,9 \%$ & $11,1 \%$ & $11,4 \%$ \\
\hline 4. Pastizales higrófilos & $65,66 \mathrm{~h}$ & $67,02 \mathrm{~h}$ & $50,43 \mathrm{~h}$ & $46,74 \mathrm{~h}$ & $48,34 \mathrm{~h}$ \\
& $11,9 \%$ & $12,2 \%$ & $9,2 \%$ & $8,5 \%$ & $8,8 \%$ \\
\hline 5. Matorrales abiertos y muy abiertos & $250,96 \mathrm{~h}$ & $250,53 \mathrm{~h}$ & $244,46 \mathrm{~h}$ & $208,17 \mathrm{~h}$ & $236,94 \mathrm{~h}$ \\
& $45,5 \%$ & $45,4 \%$ & $44,3 \%$ & $37,8 \%$ & $43,0 \%$ \\
\hline \multirow{2}{*}{ 6. Matorrales densos } & $111,57 \mathrm{~h}$ & $117,91 \mathrm{~h}$ & $145,31 \mathrm{~h}$ & $184,49 \mathrm{~h}$ \\
& $20,4 \%$ & $21,5 \%$ & $26,4 \%$ & $33,5 \%$ & $\begin{array}{c}155,04 \mathrm{~h} \\
28,2 \%\end{array}$ \\
\hline
\end{tabular}




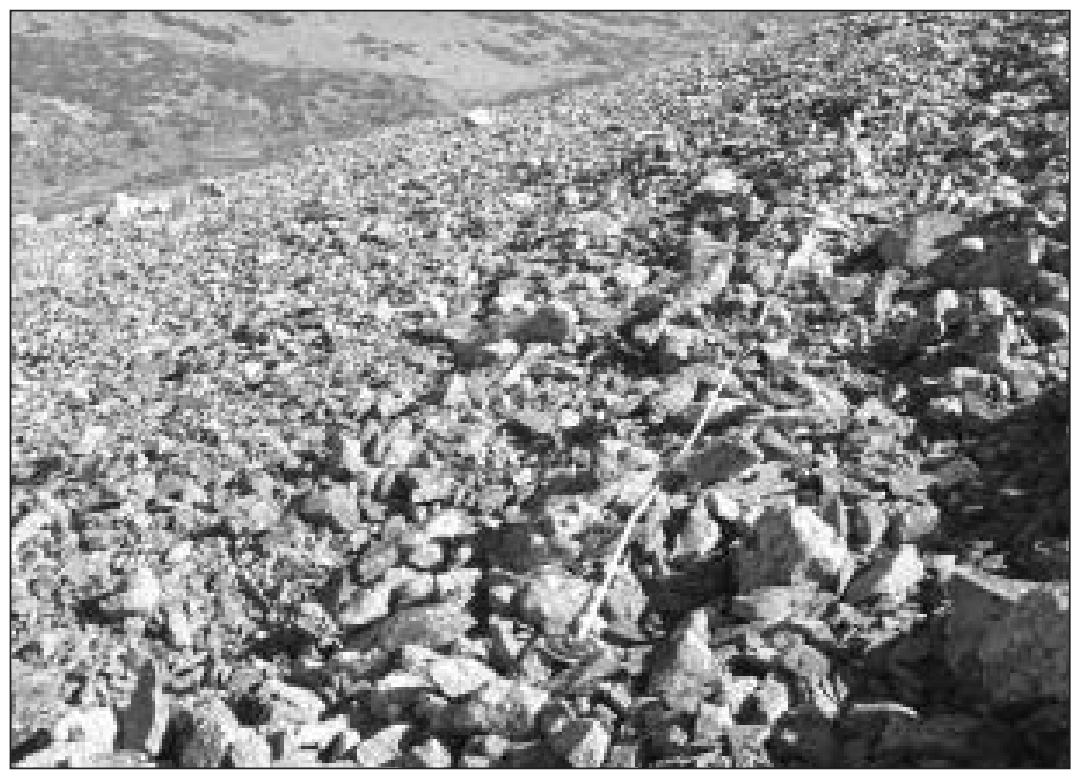

Foto 3. Pedrera en la cuenca de Valdemartín.

\subsection{Roquedales y pedreras (Foto 3)}

Aparecen como áreas descubiertas en las que aflora directamente el roquedo gneísico masivo o donde se acumulan masas sueltas y relativamente inestables de clastos angulosos (muy predominantemente de tamaño bloque) resultantes de la fragmentación del mismo. En ellas la cubierta vegetal es extremadamente laxa, limitándose a pequeños grupos de plantas acogidos en fisuras o a ejemplares aislados en huecos entre los bloques más estabilizados. Las especies más frecuentes en la vegetación fisurícola de los roquedales son Saxifraga willkomiana, Hieracium carpetanum, Criptogama crispa, Sedum brevifolium, Avenella ibérica y Agrostis rupestris, mientras que en las pedreras sueltas sólo aparecen de forma muy dispersa Agrostis truncatula, Senecio pyrenaicus, Sedum brevifolium y Avenella iberica (Rivas -Martínez., S. et al., 1989 y 1999). La extensión que suman estas áreas es pequeña (menos del $4 \%$ de la superficie de las cuencas) y se ha reducido progresivamente de forma casi imperceptible a lo largo del intervalo temporal analizado: 20,94 ha $(3,8 \%)$ en $1957 ; 19,96$ ha $(3,6 \%)$ en $1972 ; 19,77$ ha $(3,6 \%)$ en $1984 ; 19,22$ ha $(3,5 \%)$ en 1991 ; y 18,97 ha $(3,4 \%)$ en 1998.

\subsection{Ventisqueros (Fotos 4, 5 y 6 )}

Aparecen también en las fotografías aéreas como ámbitos sin recubrimiento vegetal apreciable dentro de los que, a finales de primavera o comienzos de verano (momento en que se realizaron todos los vuelos), se conservan acumulaciones o retazos más o menos importantes de nieve (Palacios et al., 2003). Situados en emplazamientos altos y abrigados orientados al $\mathrm{E}$ y el SW, en ellos afloran formaciones coluviales muy mayori- 


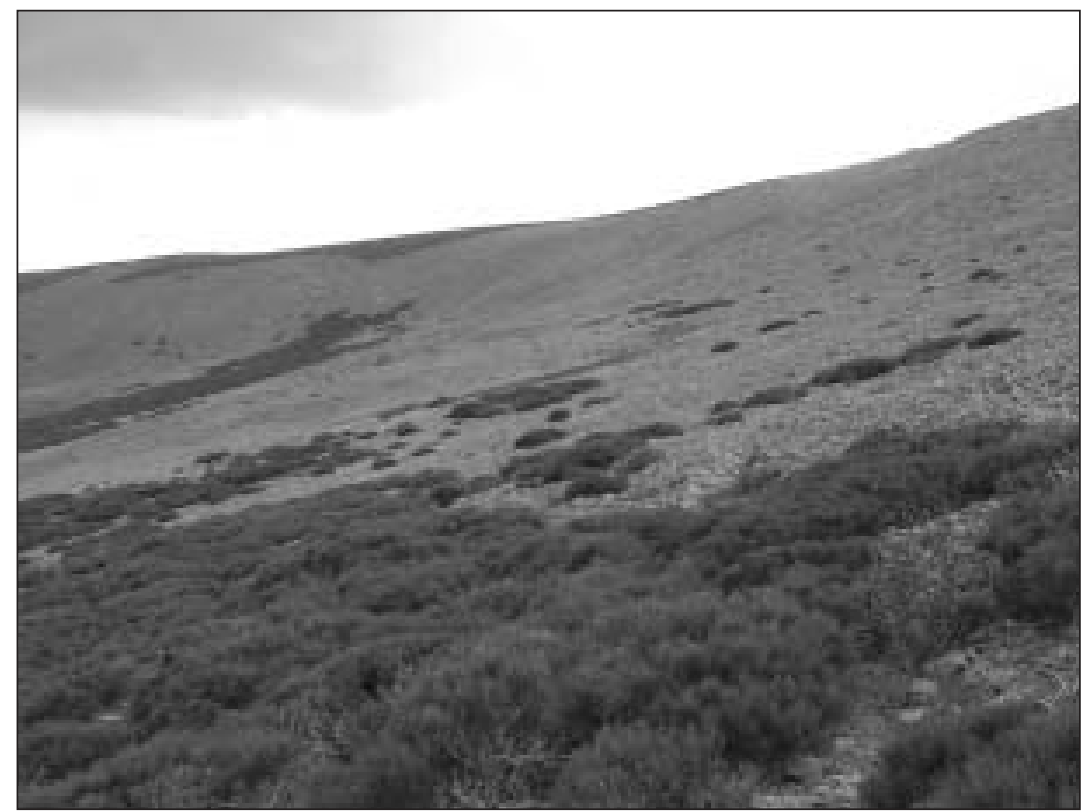

Foto 4. Ventisquero y matorral abierto de piorno en la cabecera de la cuenca de Valdemartín.

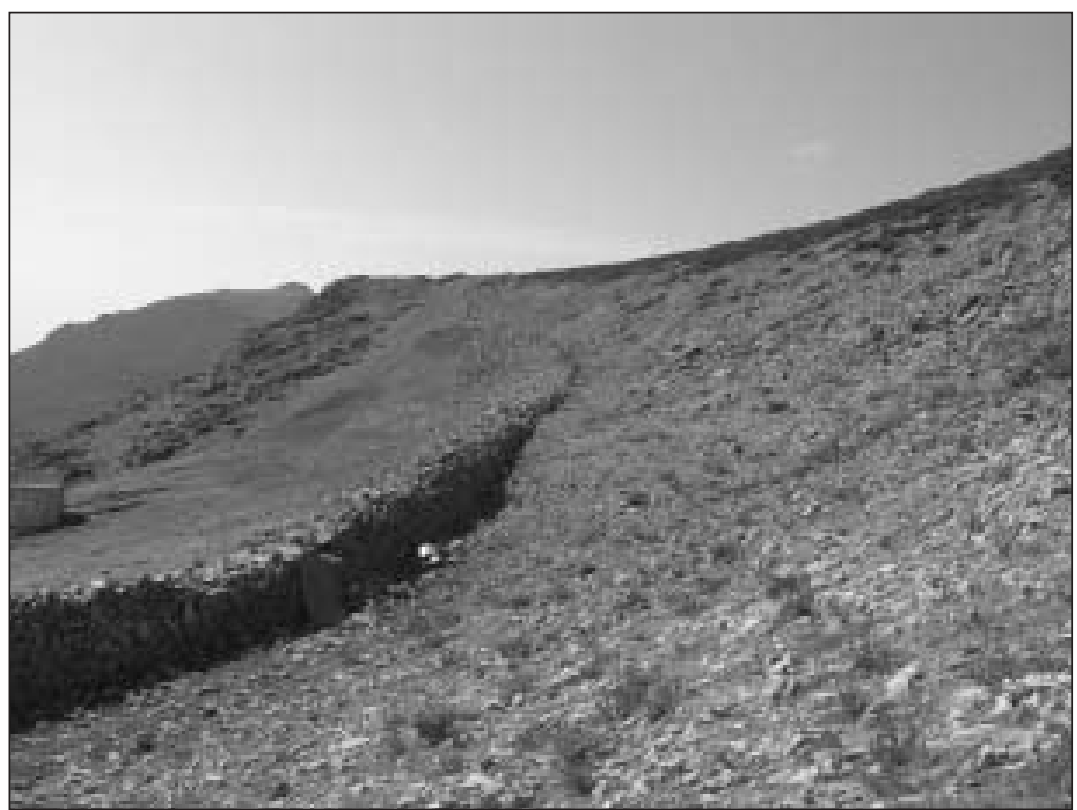

Foto 5. Ventisquero de La Condesa con el muro basal construido para facilitar la retención y la explotación de la nieve. 


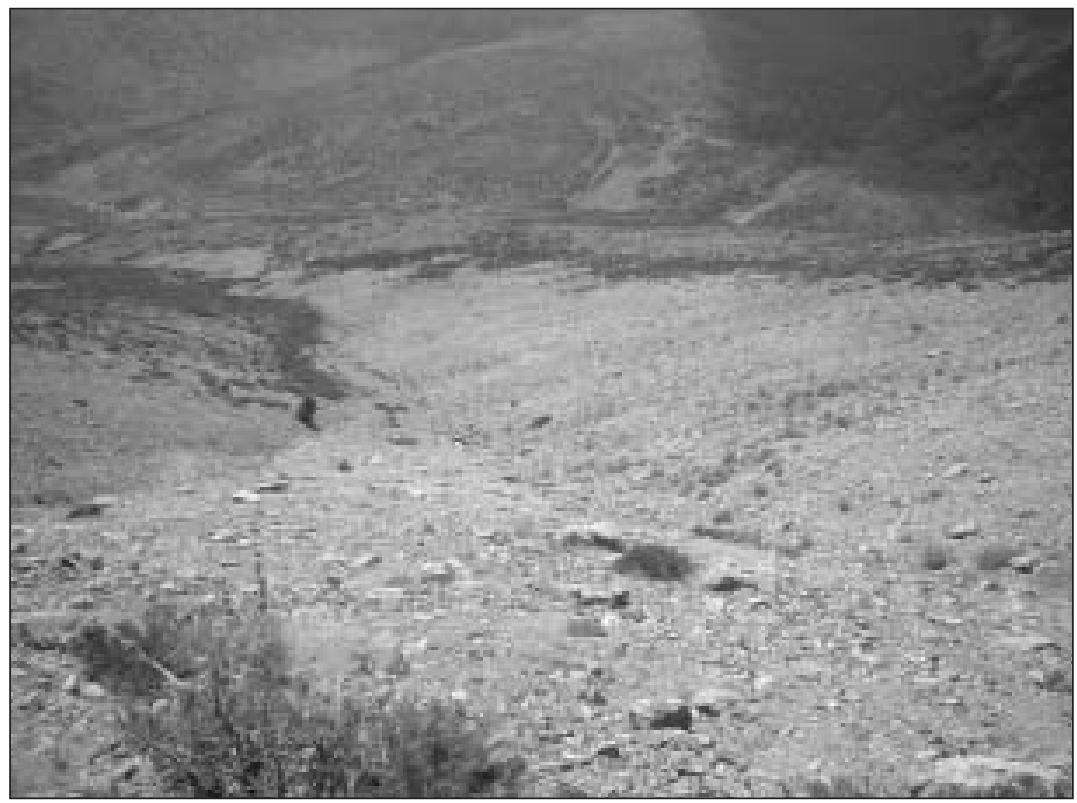

Foto 6. Ventisquero en la vertiente de sotavento de un barranco rodeado por matorrales abiertos y muy abiertos de piorno.

tariamente empastadas en cuya fracción gruesa dominan según los casos los cantos o los bloques, que pueden presentar una cierta movilidad en los niveles más superficiales del depósito. Sobre este material se desarrolla un recubrimiento herbáceo muy abierto en el que tienen una presencia mayoritaria especies quionófilas, como Mucizonia sedoides, Digitalis thapsi, Paronychia poligonifolia, Criptogama crispa y Linaria saxatilis, o plantas capaces de tolerar una larga duración de la nieve, como Agrostis truncatula, Leucantemopsis pallida, Sedum brevifolium y Senecio pyrenaicus (Fernández González, 1991; Palacios y García, 1997). Su extensión máxima, 57,62 ha equivalentes al 10,5\% de la superficie de las cuencas, se registra en 1957. A partir de entonces han sufrido una continuada y apreciable reducción: 39,47 ha $(7,2 \%)$ en $1972 ; 36,10$ ha $(6,6 \%)$ en 1984; 31,09 ha $(5,6 \%)$ en 1991 ; y 28,70 ha $(5,2 \%)$ en 1998 . Puede decirse, pues, que en la segunda mitad del siglo XX la extensión de estos ventisqueros (en alguno de los cuales, el de La Condesa, se conserva el muro de piedra que lo cerraba en su parte baja para facilitar la explotación de la nieve acumulada en él) se ha reducido, con un ritmo medio de 1,44 ha/año, hasta quedarse prácticamente en la mitad (50,1\% de reducción con respecto al área de comienzos del intervalo estudiado). 


\subsection{Pastizales psicroxerófilos (“joragales”) (Foto 7)}

Se reconocen en la fotografía aérea como espacios cubiertos por césped de muy baja talla situados en las áreas de cumbres o en altas laderas orientadas al W, pudiendo estar en este caso salpicadas por matas de Cytisus carpetanus ("piorno") o por ejemplares rastreros de Juniperus alpina ("enebro de montaña" o "jabino"). En ellos afloran mantos de alteración ricos en fracción gruesa y moderadamente afectados por procesos crionivales, sobre los que gramíneas resistentes al frío y al viento pero poco tolerantes a cubiertas nivales espesas y duraderas, entre las que destaca por su abundancia Festuca curvifolia ("joraga"), constituyen pastizales de mediana densidad, junto con otras especies capaces de soportar la dureza del clima de los sectores más altos y desabrigados (Hieracium myriadeni, Jasione crispa, Silene cialiata, Armeria caespitosa, Leucantempsis pallida y Erysimum penyalarense, entre otras) (Sanz, 1979; Rivas-Martínez et al., 1999). Estos "joragales" psicroxerófilos -que nunca han llegado a ocupar el 12\% de la extensión de las cuencas de La Condesa y Valdemartín- han registrado en el período analizado una apreciable tendencia al crecimiento espacial: en el año 1957 ocupaban 43,82 ha (7,9\%); en 1972 se habían ampliado a 55,67 ha (10,1\%); en 1984 su área se había reducido levemente a 54,46 ha $(9,9 \%)$; pero en 1991 ocupaban ya 60,84 ha $(11,1 \%)$, para alcanzar las 62,58 ha $(11,4 \%)$ en 1998 . Con un incremento medio de 0,47 ha/año, su superficie ha aumentado por lo tanto en más de un $40 \%$.

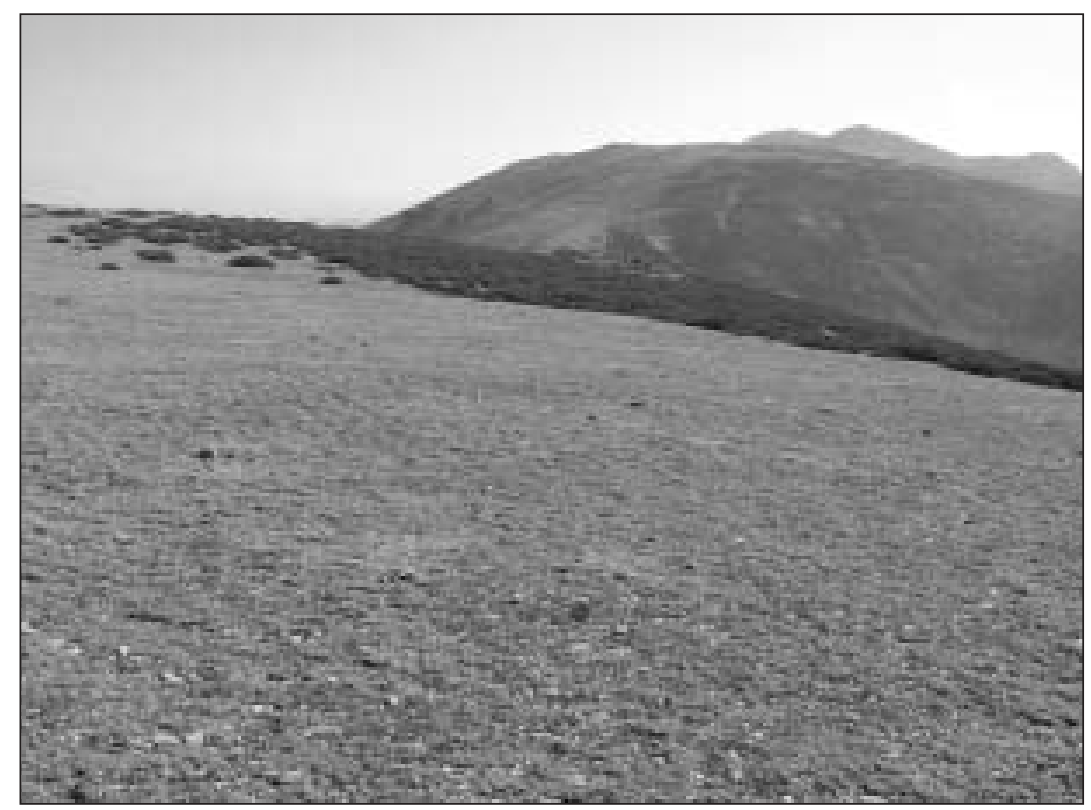

Foto 7. Pastizal psicroxerófilo en la Bola del Mundo, sobre la cabecera de la cuenca de La Condesa. 


\subsection{Pastizales húmedos (“cervunales") (Foto 8)}

Se diferencian claramente en la fotografía aérea como áreas colonizadas por prados muy densos situadas siempre en sectores particularmente ricos en agua y favorables para la retención de la humedad (fondos de valle, cercanías de manantiales y franjas basales de ventisqueros). En ellas el sustrato rocoso se encuentra recubierto de forma prácticamente continua por formaciones edáficas de textura y naturaleza turbosas, cuyo espesor es superior por lo normal a $1 \mathrm{~m}$, y son frecuentes los enclaves pantanosos (con turberas parcialmente activas en algunos casos). La combinación de estos suelos orgánicos oscuros dotados de una gran capacidad de captación de humedad con unos aportes hídricos abundantes y casi continuos, dentro de un ambiente general marcado por el frío y la nieve, propicia el desarrollo de pastizales densos siempre verdes compuestos por gramíneas de montaña particularmente higrófilas, entre las que destacan por su abundancia Nardus stricta (“cervuno") y Festuca iberica. Estas dos especies dominantes se encuentran acompañadas por Luzula campestris, Hieracium pilosella, Ranunculus bulbosus, Polytrichium juniperinum, Galium rivulare y Trifolium repens, en los sectores no saturados de agua, y por Sphagnum sp., Carex nigra, Carex echinata, Viola palustris, Erica tetralix y Drosera rotundifolia, en los sectores pantanosos o próximos a los cursos de los arroyos (Sanz, 1979; Rivas -Martínez et al., 1999). La extensión de estos “cervunales", que era de 65,66 ha $(11,9 \%)$ en 1957 se incrementó ligeramente en la primera parte del período estudiado, llegando a un máximo de 67,02 ha (12,2\%) en 1972; a partir de este

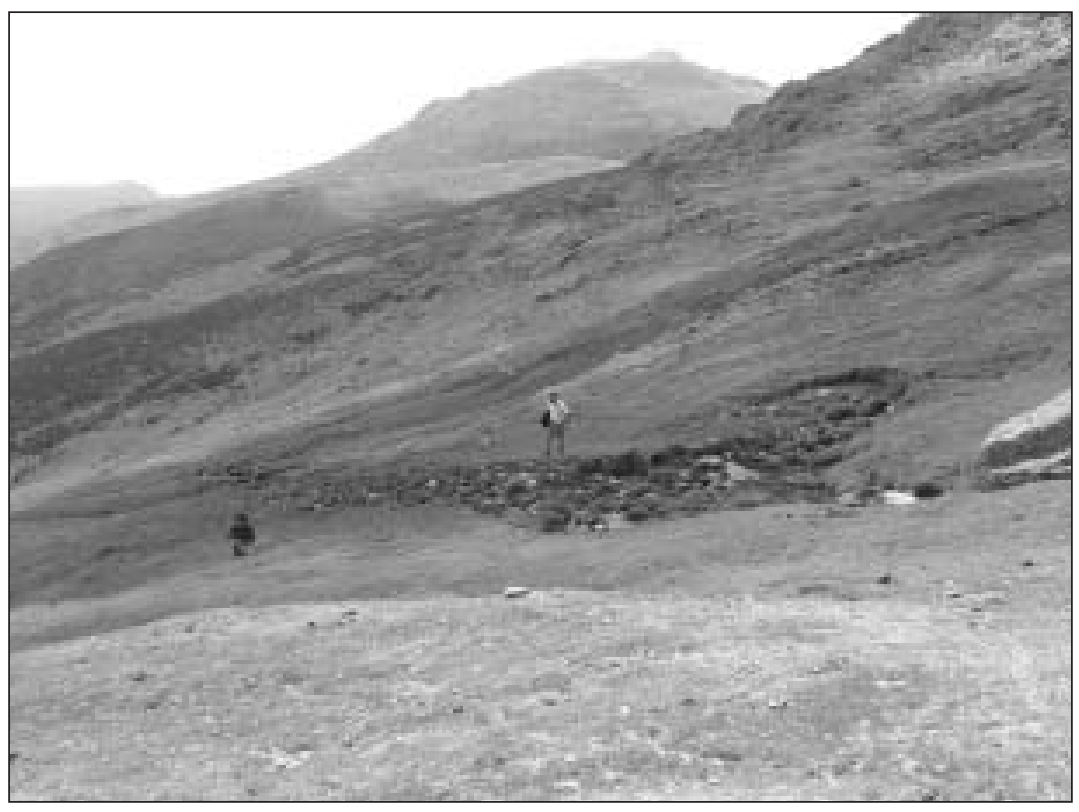

Foto 8. Pastizal higrófilo ("cervunal”) con turbera al pie del Ventisquero de La Condesa. 
año se ha registrado, primero, una apreciable disminución - 50,43 ha $(9,2 \%)$ en 1981 y 46,74 ha $(8,5 \%)$ en 1991 - y, después, una práctica estabilización, con 48,34 ha $(8,8 \%$ de la superficie total del territorio) en 1998. En todo caso, el ámbito de los prados higrófilos se ha reducido de forma apreciable ( 0,43 ha menos al año, por término medio) en el período de referencia, siendo al final de éste un $27 \%$ menos extenso que a mediados del siglo XX.

\subsection{Matorrales abiertos o muy abiertos de "piorno" (Foto 9)}

Los matorrales de mediana o baja densidad compuestos de forma prácticamente exclusiva por Cytisus carpetanus ("piorno") se diferencian con claridad en las sucesivas coberturas de fotografía aérea de las cuencas de La Condesa y Valdemartín, en todas las cuales constituyen la unidad de paisaje mayoritaria en cuanto a superficie, ocupando siempre más del 40\% del territorio (Rivas-Martínez et al., 1989; Fernández González, 1991). Se trata de ámbitos en los que los ejemplares o grupos de este arbusto de la familia de las leguminosas dejan entre sí espacios libres, ocupados sólo por vegetación herbácea y bien reconocibles en las imágenes, cuya extensión relativa puede llegar a ser tan grande que sitúe a estas formaciones en la transición entre un verdadero matorral y un pastizal psicroxerófilo salpicado de matas. Se extienden por la mayor parte de las laderas de ambas cuencas, aunque abundan más en las orientadas a Poniente, colonizando prioritariamente depósitos coluviales de textura media o fina y mantos de alteración

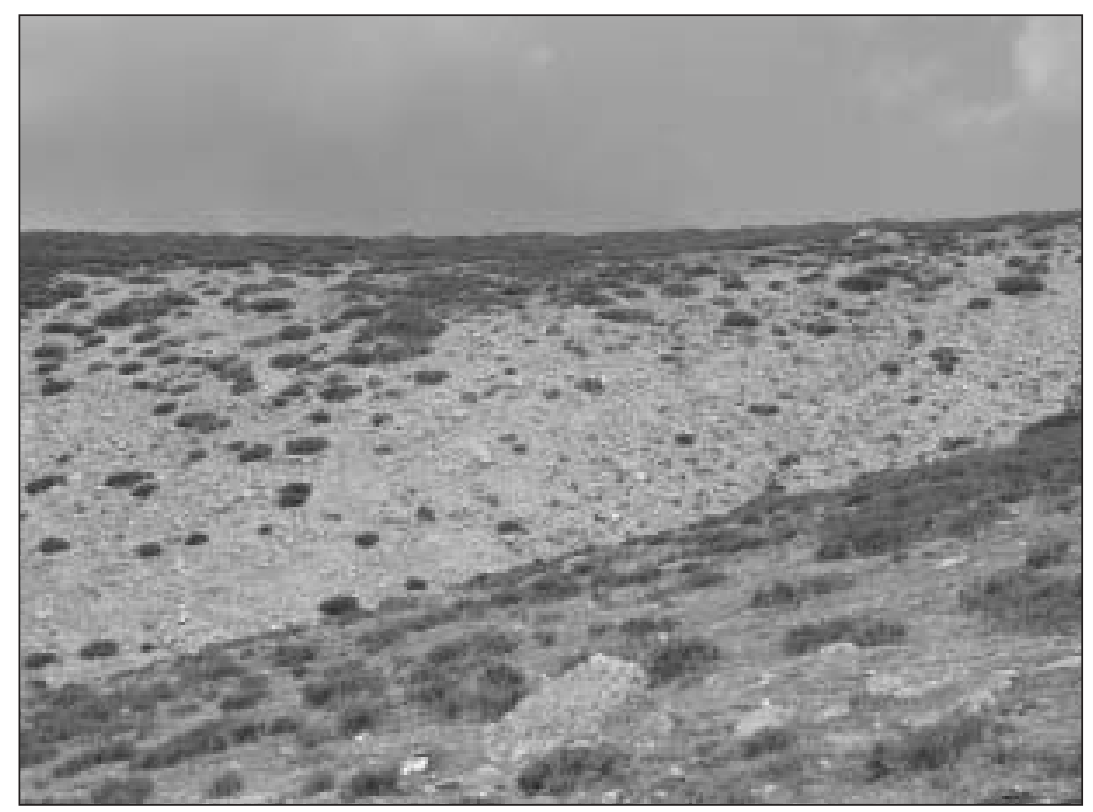

Foto 9. Matorral muy abierto de piorno en las proximidades de un ventisquero enmarcado en la parte superior por matorral denso (cuenca de Valdemartín). 
homogéneos con pocos afloramientos de roca sana. En su estrato arbustivo, claramente monoespecífico, tiene alguna presencia Adenocarpus hispanicus ("cambroño" o "codeso") y en el estrato herbáceo predominan las gramíneas (sobre todo Avenella iberica, Festuca curvifolia y Koeleria caudata) y se encuentran con frecuencia Rumex suffruticosus y Rumex acetosella (Rivas-Martínez et al, 1999). Adaptados a recubrimientos nivales de mediano espesor y duración y afectados hasta tiempos muy próximos al período analizado por los incendios provocados sistemáticamente por los ganaderos con el objeto de incrementar los pastos, las dimensiones de su área se han reducido, aunque no de forma sustancial. A comienzos del indicado período -en 1957- estos "piornales abiertos y muy abiertos" registraban su máximo desarrollo, ocupando una superficie de 250,96 ha $(45,5 \%$ del total), la cual apenas había variado en 1972, año en que se extendían por 250,53 ha (45,4\%); en 1984 ya se aprecia una cierta reducción, hasta 244,46 ha $(44,3 \%)$, que a partir de entonces se hace más marcada para llegar en 1991 a la mínima superficie, con 208,17 ha (37,8\%). En la última década del siglo XX el sentido de la evolución espacial se invierte y han recuperado territorio para contar en 1998 con 236,94 ha $(43,00 \%)$. No obstante, en el conjunto del período la tendencia ha sido suavemente regresiva, con un ritmo medio de descenso de 0,33 ha/año y una disminución de sólo el $5,6 \%$ con respecto a la superficie ocupada a comienzos de intervalo estudiado.

\subsection{Matorrales densos de "piorno" y de "jabino" y "piorno" (Foto 10)}

Aparecen en las imágenes como áreas densamente cubiertas por vegetación arbustiva localizadas en sectores próximos a las cumbres, con frecuencia en el entorno de los ventisqueros, y en sectores de ladera donde son numerosos los afloramientos directos del roquedo o donde los depósitos coluviales incluyen bloques de gran calibre. En ellas el "piorno" (Cytisus carpetanus), solo o asociado con el "jabino" (Juniperus alpina), constituye matorrales de fuerte densidad en los que los ejemplares de estas dos especies apenas dejan huecos donde pueda desarrollarse un verdadero pastizal, aunque entre ellos existe un estrato herbáceo laxo, pero de notable riqueza florística, en el que tienen una presencia significativa Avenella iberica, Arrenatherum elatius, Festuca curvifolia, Hieracium myriadenum, Thymus praecox, Senecio pyrenaicus, Luzula lactea y Rumex acetosella (Rivas-Martínez, 1989 y 1999). Estos “piornales densos” y "piornal-jabinales" han ocupado en los cincuenta años analizados el segundo lugar en cuanto a extensión superficial dentro del conjunto de las cuencas de La Condesa y Valdemartín, colonizando siempre más del $20 \%$ de su territorio, y han registrado una clara tendencia progresiva a lo largo de este período (interrumpida solamente en la última década). La superficie cubierta por ellos, que era de 111,57 ha (20,4\% del total) en 1957 y de 117,91 ha $(21,5 \%)$ en 1972 , había crecido en 1984 hasta 145,31 ha $(26,4 \%)$ y hasta 184,49 ha $(33,5 \%)$ en 1991; a partir de este año se produce una reducción apreciable, de modo que el área de los matorrales densos había descendido en 1998 a 155,04 ha (28,2\%). En todo caso la expansión de estas formaciones arbustivas de alta densidad, capaces de tolerar una cubierta de nieve relativamente duradera pero sensibles en su mayor parte a los incrementos fuertes en el espesor de ésta, constituye uno de los principales procesos que se registran en el intervalo de referencia: su progresión ha sido de 1,1 ha/año y su área es a finales del siglo XX un $39 \%$ mayor que a mediados del mismo. 


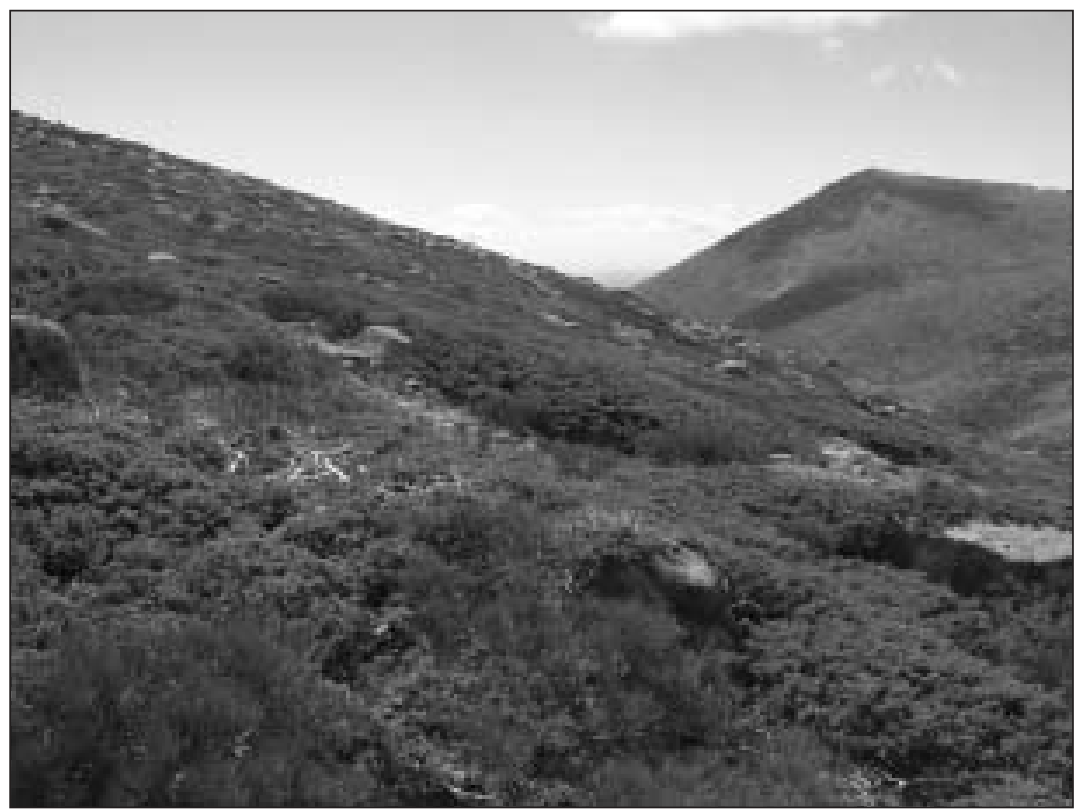

Foto 10. Matorral denso de jabino y piorno sobre un afloramiento granítico de la cuenca de Valdemartín.

\section{Sentido y ritmo de las principales tendencias evolutivas de la cubierta vegetal}

Los datos expuestos permiten afirmar que en las altas cuencas de la Condesa y Valdemartín se han registrado a lo largo de la segunda mitad del pasado siglo cambios significativos en el reparto del territorio entre los diversos tipos de paisaje vegetal y reconocer que dichos cambios han conducido a una reducción de los ventisqueros, de los pastizales higrófilos y de los piornales abiertos y muy abiertos y a una expansión de los pastizales psicroxerófilos y de los matorrales densos de piorno y jabino. También se ha producido una reducción de los roquedales y pedreras, pero las dimensiones de ésta han sido tan reducidas que pueden considerase un componente estable dentro del intervalo temporal considerado.

Tanto desde el punto de vista del valor porcentual del cambio como desde la perspectiva del ritmo medio de éste la reducción de los ventisqueros y la expansión de los matorrales densos son los procesos de mayor importancia, seguidos por el crecimiento de los pastizales psicroxerófilos y la disminución de la superficie de los pastizales higrófilos; menos significativa estadísticamente es la reducción de los matorrales abiertos, que son -como se ha dicho- el tipo de cubierta vegetal mayoritario a lo largo de todo el período analizado en las cuencas de La Condesa y Valdemartín. Pero entre ellos no sólo existen diferencias de sentido y de ritmo medio, sino también de modo de evolución: 
como se aprecia en los diagramas evolutivos y en las líneas polinómicas de tendencia, la superficie de los ventisqueros se ha ido reduciendo de forma continua y con rimo decreciente a lo largo de todo el período de referencia, al tiempo que los matorrales densos han ampliado su área también de forma continua pero con ritmo creciente (y sólo hasta la última década del siglo XX, en la que hay un cambio de sentido cuya persistencia aún no es posible establecer); la reducción de los cervunales, por su parte, ha tenido un ritmo muy bajo en los años cincuenta y sesenta y se ha acelerado progresivamente a partir de los setenta, marcando una tendencia contraria a la de los pastizales psicroxerófilos, cuya superficie se incrementó con relativa fuerza a comienzos del período y luego ha ido disminuyendo su ritmo de crecimiento; y, finalmente, el descenso de la superficie ocupada por matorrales de baja densidad ha sido un proceso de ritmo muy lento y regular hasta los ochenta que ha sufrido después una brusca aceleración (interrumpida, lo mismo que la expansión de los matorrales densos, en los últimos años del siglo).

\section{Caracterización de las condiciones climáticas y de sus modificaciones}

Con el objeto de apreciar su mayor o menor correspondencia con el sentido, el ritmo y la forma de los indicados procesos de cambio en la cubierta vegetal se han seleccionado las 18 variables climáticas anuales y estacionales más relacionadas con los condicionamientos ambientales de las plantas y comunidades de alta montaña: 3 termométricas de rango anual; 4 termométricas de rango estacional; 2 referentes a volúmenes pluviométricos (una de rango anual y otra de rango estacional); 3 referentes a frecuencia anual de precipitaciones y de duración anual de la nieve; y 6 nivométricas de rango estacional. Se han obtenido los datos correspondientes a ellas registrados en el observatorio meteorológico de Puerto de Navacerrada en la totalidad del período 1951-2000 y con ellos se han elaborado los correspondientes diagramas evolutivos y líneas de tendencia (Figs 4, 5 y 6). Se han hallado igualmente sus valores medios en cada uno de los cinco intervalos o tramos en que se ha dividido el período analizado, con el objeto de apreciar las diferencias entre el primero y el último de ellos (Tablas 2-6).

Tabla 2. Valores termométricos anuales medios correspondientes a los cinco tramos y al conjunto del período 1951-2000 (Observatorio de Puerto de Navacerrada).

\begin{tabular}{|c|c|c|c|c|c|c|}
\hline & $\mathbf{1 9 5 1 - 1 9 5 6}$ & $\mathbf{1 9 5 7 - 1 9 7 1}$ & $\mathbf{1 9 7 2 - 1 9 8 3}$ & $\mathbf{1 9 8 4 - 1 9 9 0}$ & $\mathbf{1 9 9 1 - 2 0 0 0}$ & $\underline{\mathbf{1 9 5 1 - 2 0 0 0}}$ \\
\hline T media anual & 5,75 & 5,83 & 5,92 & 6,74 & 6,87 & $\mathbf{6 , 1 8}$ \\
\hline T max media a. & 9,52 & 9,33 & 9,21 & 10,37 & 10,72 & $\mathbf{9 , 7 5}$ \\
\hline T min media a. & 2,00 & 2,39 & 2,72 & 3,17 & 3,06 & $\mathbf{2 , 6 7}$ \\
\hline
\end{tabular}



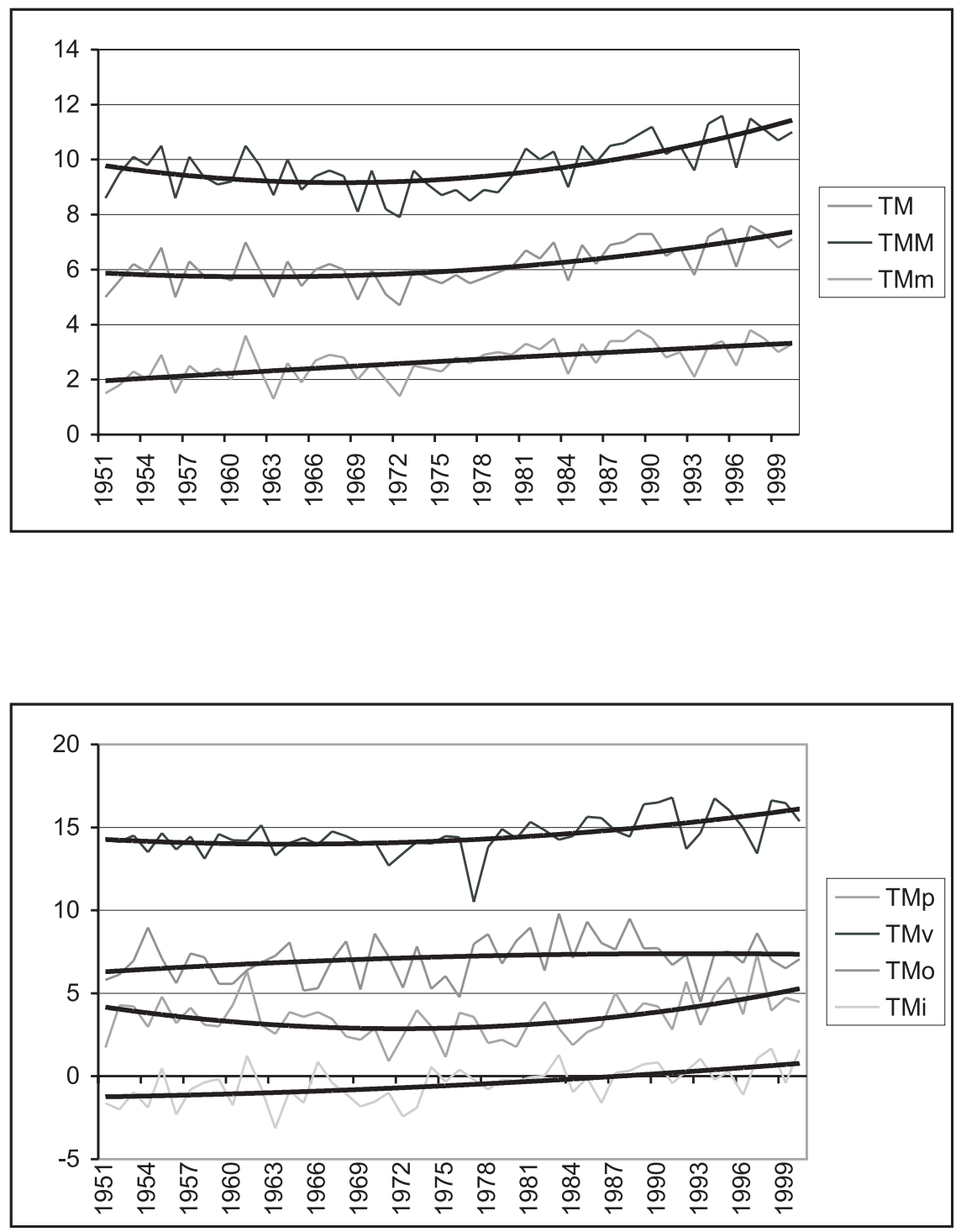

Figura 4. Evolución y línea polinómica de tendencia de los valores termométricos anuales y estacionales a lo largo de la segunda mitad del siglo XX (Observatorio de Puerto de Navacerrada). [TM: Temperatura media anual. TMM: Temperatura media anual de las máximas. TMm: Temperatura media anual de las mínimas. TMp: Temperatura media de primavera. TMv: Temperatura media de verano. TMo: Temperatura media de otoño. Tmi: Temperatura media de invierno]. 


\subsection{Variables termométrica}

Todos los indicadores anuales y estacionales ponen de manifiesto una tendencia clara al incremento del nivel de las temperaturas en las áreas culminantes de la Sierra de Guadarrama a lo largo de la segunda mitad del siglo XX. La temperatura media anual ha aumentado en ellas un $19,5 \%$ y la temperatura media anual de las máximas lo ha hecho un $12,6 \%$; pero lo más significativo es que la temperatura media anual de las mínimas ha crecido un 53\% (Tabla 2). Igualmente, el nivel térmico medio ha aumentado en todas las estaciones del año, pero, mientras que el incremento de la temperatura media de verano y de la temperatura media de otoño han sido francamente moderados ( $9,6 \%$ y $2,7 \%$ respectivamente), el de la temperatura media de primavera ha sido muy notable $(32,3 \%)$ y el de la temperatura media de invierno realmente espectacular $(127,5 \%)$ (Tabla 3).

Tabla 3. Valores termométricos estacionales medios correspondientes a los cinco tramos y al conjunto del período 1951-2000 (Observatorio de Puerto de Navacerrada).

\begin{tabular}{|l|c|c|c|c|c|c|}
\hline & $\mathbf{1 9 5 1 - 1 9 5 6}$ & $\mathbf{1 9 5 7 - 1 9 7 1}$ & $\mathbf{1 9 7 2 - 1 9 8 3}$ & $\mathbf{1 9 8 4 - 1 9 9 0}$ & $\mathbf{1 9 9 1 - 2 0 0 0}$ & $\underline{\mathbf{1 9 5 1 - 2 0 0 0}}$ \\
\hline T media Prim. & 3,53 & 3,23 & 2,89 & 3,53 & 4,67 & $\mathbf{3 , 5 4}$ \\
\hline T media Ver. & 14,13 & 14,10 & 14,03 & 15,40 & 15,48 & $\mathbf{1 4 , 5 5}$ \\
\hline T media Oto. & 6,76 & 6,73 & 7,15 & 8,15 & 6,94 & $\mathbf{7 , 0 8}$ \\
\hline T media Inv. & $-1,38$ & $-0,88$ & $-0,33$ & $-0,08$ & 0,38 & $\mathbf{- 0 , 4 4}$ \\
\hline
\end{tabular}

\subsection{Variables pluviométricas}

Tanto la pluviosidad anual como la pluviosidad invernal muestran una tendencia decreciente, moderada en ambos casos pero algo más apreciable en el segundo: el volumen de agua precipitada durante el invierno, mayoritariamente en forma de nieve, ha sido en los últimos años del período un $17,1 \%$ inferior al del tramo inicial del mismo (Tabla 4).

Tabla 4. Volúmenes pluviométricos recibidos por término medio al año y en la estación invernal correspondientes a los cinco tramos y al conjunto del período 1951 2000 (Observatorio de Puerto de Navacerrada).

\begin{tabular}{|l|c|c|c|c|c|c|}
\hline & $\mathbf{1 9 5 1 - 1 9 5 6}$ & $\mathbf{1 9 5 7 - 1 9 7 1}$ & $\mathbf{1 9 7 2 - 1 9 8 3}$ & $\mathbf{1 9 8 4 - 1 9 9 0}$ & $\mathbf{1 9 9 1 - 2 0 0 0}$ & $\underline{\mathbf{1 9 5 1 - 2 0 0 0}}$ \\
\hline P anual & 1377,33 & 1447,80 & 1457,92 & 1231,86 & 1209,70 & $\mathbf{1 3 6 3 , 9 2}$ \\
\hline P invernal & 460,00 & 453,87 & 509,75 & 382,14 & 381,20 & $\mathbf{4 4 3 , 4 4}$ \\
\hline
\end{tabular}



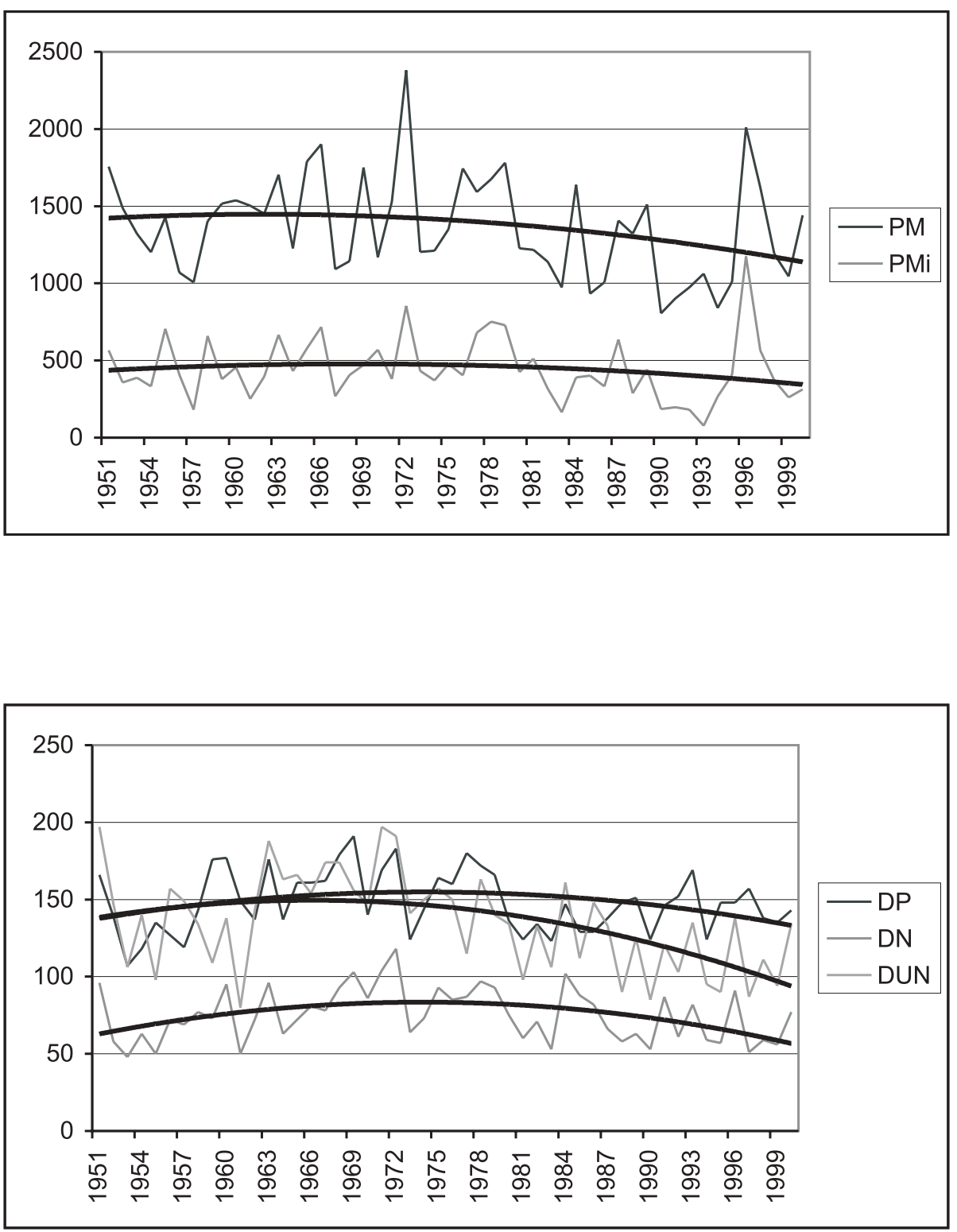

Figura 5. Evolución y línea polinómica de tendencia de los valores referentes a volumen y frecuencia de las precipitaciones a lo largo de la segunda mitad del siglo XX (Observatorio de Puerto de Navacerrada). [PM: Pluviosidad anual. PMi: Pluviosidad invernal. DP: Número anual de días de precipitación. DN: Número anual de días de nevada. DUN: Número anual de días de permanencia de la nieve sobre el suelo]. 


\subsection{Variables pluvionivométricas anuales}

Aunque ni el número anual de días de nevada y el número anual de días de precipitación han sufrido cambios importantes y éstos han mostrado una suave tendencia al incremento (del 5,4\% y del 10,6\% respectivamente), la duración anual de la nieve sobre el suelo se ha reducido de forma apreciable. A una altura análoga a la de la parte baja de las cuencas de la Condesa y Valdemartín la persistencia de la cubierta nival durante el año se ha reducido en 30 días y se ha hecho un 21,3\% más corta que a mediados del siglo XX (Tabla 5).

Tabla 5. Número medio anual de días de precipitación y nevada y de permanencia de la nieve sobre el suelo en los cinco tramos y en el conjunto del período 1951-2000

(Observatorio de Puerto de Navacerrada).

\begin{tabular}{|l|c|c|c|c|c|c|}
\hline & $\mathbf{1 9 5 1 - 1 9 5 6}$ & $\mathbf{1 9 5 7 - 1 9 7 1}$ & $\mathbf{1 9 7 2 - 1 9 8 3}$ & $\mathbf{1 9 8 4 - 1 9 9 0}$ & $\mathbf{1 9 9 1 - 2 0 0 0}$ & $\mathbf{1 9 5 1 - 2 0 0 0}$ \\
\hline D Precip/año & 132,00 & 158,47 & 150,83 & 138,00 & 146,00 & $\mathbf{1 4 8 , 1 0}$ \\
\hline D nieve/año & 64,50 & 80,80 & 80,75 & 73,14 & 68,00 & $\mathbf{7 5 , 2 0}$ \\
\hline Dur nieve/año & 140,83 & 151,47 & 139,83 & 122,00 & 110,80 & $\mathbf{1 3 5 , 1 4}$ \\
\hline
\end{tabular}

\subsection{Variables nivométricas estacionales}

De acuerdo con los datos proporcionados por el observatorio meteorológico de Puerto de Navacerrada, la duración de la cubierta nival se ha reducido en mayor o menor medida en las tres estaciones del año en las que normalmente está presente, a pesar de que en dos de ellas la frecuencia de las nevadas apenas ha variado y en otra se ha incrementado. Así, el número de días de nevada en otoño ha crecido de forma significativa $(35,5 \%)$, al tiempo que la duración de la nieve en otoño apenas ha disminuido un $1,9 \%$. Por su parte, el número de días de nevada en invierno se ha reducido ligeramente $(5,7 \%)$, mientras que la duración de la nieve en invierno lo ha hecho en una medida algo mayor $(12,3 \%)$. La evolución más significativa se ha producido en el trimestre primaveral, ya que, sin que el número de días de nevada en primavera haya disminuido nada más que un $9,9 \%$, la duración de la nieve en primavera ha pasado a ser en la última década del período analizado un 41,4\% inferior (22,63 días menos) a la registrada en los primeros años de la misma (Tabla 6). 
Tabla 6. Número medio estacional de días de nevada y de permanencia de la nieve sobre el suelo registrado en los cinco tramos y en el conjunto del período 1951-2000

(Observatorio de Puerto de Navacerrada).

\begin{tabular}{|l|c|c|c|c|c|c|}
\hline & $\mathbf{1 9 5 1 - 1 9 5 6}$ & $\mathbf{1 9 5 7 - 1 9 7 1}$ & $\mathbf{1 9 7 2 - 1 9 8 3}$ & $\mathbf{1 9 8 4 - 1 9 9 0}$ & $\mathbf{1 9 9 1 - 2 0 0 0}$ & $\mathbf{1 9 5 1 - 2 0 0 0}$ \\
\hline D nieve/otoño & 9,00 & 13,20 & 10,50 & 9,86 & 11,20 & $\mathbf{1 1 , 1 8}$ \\
\hline Dur nieve/oto. & 11,83 & 16,40 & 10,25 & 10,57 & 11,60 & $\mathbf{1 2 , 6 0}$ \\
\hline D nieve/invier. & 34,67 & 39,93 & 37,58 & 35,00 & 32,70 & $\mathbf{3 6 , 6 0}$ \\
\hline Dur nieve/inv. & 74,16 & 81,47 & 71,75 & 70,29 & 65,00 & $\mathbf{7 3 , 4 0}$ \\
\hline D nieve/prim. & 20,83 & 27,67 & 32,50 & 27,43 & 22,90 & $\mathbf{2 7 , 0 2}$ \\
\hline Dur nieve/pri. & 54,83 & 53,60 & 57,83 & 41,86 & 32,20 & $\mathbf{4 9 , 2 4}$ \\
\hline
\end{tabular}

\section{Sentido y ritmo de las modificaciones de los parámetros climáticos}

En pocos casos las variaciones estadísticas de los parámetros climáticos anuales y estacionales responden en el área a cambios regulares y progresivos. Sólo la temperatura media anual de las mínimas y la duración de la nieve en otoño se han modificado (una al alza y otra a la baja) conforme a líneas de tendencia rectilíneas a lo largo de las cinco décadas. Lo más normal es que estas líneas sean curvas, presentando la mayor parte de ellas inflexiones más o menos apreciables. Así, los valores termométricos anuales y estacionales, con la indicada excepción, muestran una suave tendencia al descenso a comienzos del período estudiado, la cual se mantiene hasta un momento situado casi siempre en el tercio central de éste (entre 1966 y 1983); a partir de él dichos valores manifiestan una clara y progresiva tendencia a incrementarse conforme la fecha se aproxima al año 2000. Por su parte, los registros referentes a la pluviosidad y a la nieve, salvo el anteriormente indicado, muestran una tendencia al crecimiento relativamente marcada en algunos casos (como el número anual de días de nevada, el numero de días de nevada en primavera y la duración de la nieve en primavera) hasta, más o menos, la década de los años setenta para seguir a partir de entonces una tendencia descendente muy apreciable y progresiva. De acuerdo con todo ello - y desde una perspectiva estrictamente climática- el período de referencia podría dividirse en tres partes: una inicial moderadamente fría, lluviosa y propicia a la innivación, a lo largo de la que el nivel térmico tiende a disminuir y a aumentar los stocks de agua y de nieve; otra central en la que se alcanzan los niveles térmicos más bajos y los mayores grados de pluviosidad y nivosidad y donde se invierte el sentido de las líneas de tendencia termométricas y pluvio-nivométricas; y otra final apreciablemente menos fría y menos rica en lluvia y nieve, a lo largo del que la tendencia ascendente de los registros termométricos y la descendente de los valores pluvio-nivométricos se acusa con especial claridad. 

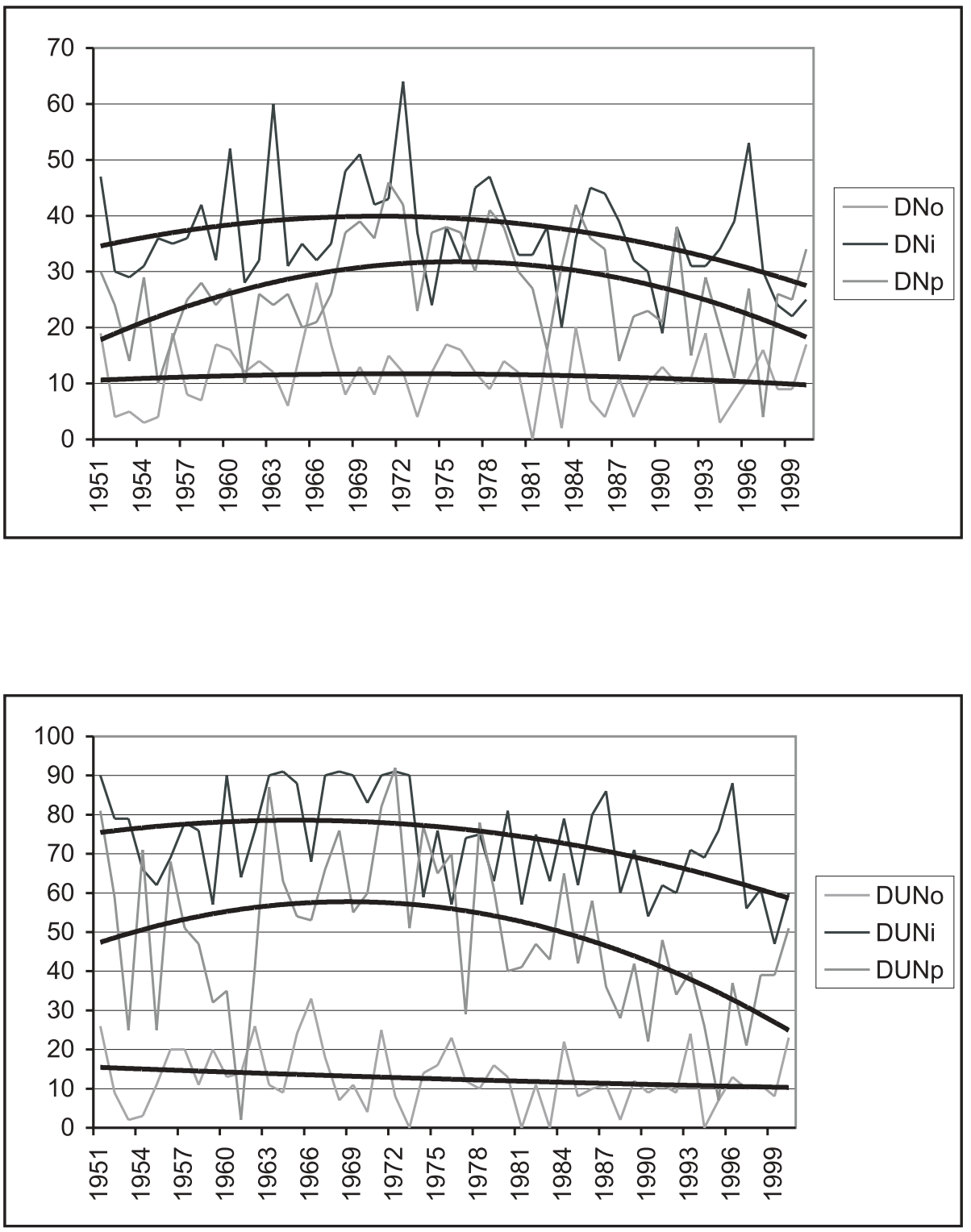

Figura 6. Evolución y línea polinómica de tendencia de los valores nivométricos estacionales a lo largo de la segunda mitad del siglo XX (Observatorio de Puerto de Navacerrada). [Dno: Número de días de nevada en otoño. Dni: Número de días de nevada en invierno. DNp: Número de días de nevada en primavera. DUNo:

Número de días de permanencia de la nieve en otoño; DUNi: Número de días de permanencia de la nieve en invierno. DUNp: Número de días de permanencia de la nieve en primavera]. 
Siguiendo las pautas evolutivas indicadas, los principales procesos de modificación climática registrados en el área donde se ubican las cuencas de La Condesa y Valdemartín son el aumento continuado de la temperatura media de invierno y de la temperatura media anual de las mínimas, junto con la disminución progresivamente acelerada en la última parte del período analizado de la duración de la nieve en primavera. También son significativos, marcando tendencias complementarias con los anteriores, el aumento progresivo de la temperatura media de primavera y de la temperatura media de las máximas y la disminución igualmente progresiva de la duración anual de la nieve y de la pluviosidad invernal.

Así pues, el análisis estadístico de la evolución de 18 indicadores meteorológicos anuales y estacionales a lo largo del período 1951-2000 ha permitido reconocer una tendencia al incremento en todos los valores termométricos y una tendencia a la disminución en la práctica totalidad de los valores pluviométricos y nivométricos, de modo que a finales de dicho período el ambiente climático de las cumbres y altas laderas del Guadarrama central -donde se ubican las cuencas de La Condesa y Valdemartín- es menos frío, menos lluvioso y menos afectado por la presencia de la nieve que a mediados del siglo XX. Existen, no obstante, cinco variables en las que estas tendencias se manifiestan de forma tan escasa que pueden considerarse prácticamente estables; este es el caso del número de días de precipitación al año, el número de días de nevada al año, el número de días de nevada en primavera, el número de días de nevada en otoño y la temperatura media de otoño. No se ha producido, pues, un cambio apreciable en la frecuencia anual de las lluvias y de las precipitaciones nivales ni en la frecuencia con que nieva en primavera y en otoño. Por el contrario, existen seis variables -las que se acaban de señalar en el apartado anterior, al definir las modificaciones climáticas principales- que, teniendo en cuenta el valor porcentual de su incremento o su disminución a lo largo del período, han registrado un cambio altamente significativo. Como consecuencia de los cambios producidos en ellas el área analizada se ha hecho globalmente menos fría, menos proclive a los fuertes descensos nocturnos de la temperatura y menos favorable a la persistencia de la cubierta nival y en ella el invierno y la primavera se han ido haciendo menos fríos y con una más corta persistencia de la nieve sobre el suelo. Todo ello conforma una modificación ambiental cuya incidencia en la evolución de la vegetación supraforestal de las cuencas de la cabecera del Manzanares parece una hipótesis lógica y plausible.

\section{Resultados: correlación entre la evolución espacial de las facies vegetales y la modificación de los parámetros climáticos}

Con el objeto de avanzar en la confirmación de la hipótesis planteada o, al menos, de valorar de forma precisa el nivel de covariación existente entre la extensión de las 6 facies vegetales y los 18 parámetros climáticos se han obtenido los Índices de correlación que figuran en la Tabla 7. Conforme a ellos la temperatura media anual de las mínimas, la temperatura media de invierno y la temperatura media anual son las variables climáticas más claramente relacionadas con la dinámica espacial de las facies vegetales: el 
valor medio de su correlación con la superficie ocupada por dichas facies se sitúa entre 0,80 y 0,90 y prácticamente con todas ellas alcanza un nivel altamente significativo. Viene a continuación la temperatura media de verano, cuya correlación media es de 0,75 y que covaría muy significativamente con tres de los tipos de cubierta vegetal, y tras ella se encuentran la duración anual de la nieve, la duración de la nieve en primavera y la temperatura media anual de las máximas, con correlaciones medias entre 0,65 y 0,70 y niveles de covariación apreciables con la mitad de los tipos de vegetación. En el otro extremo, como parámetros climáticos menos influyentes, están el número de días de nevada al año, el número de días de nevada en primavera, el número de días de precitación al año, el número de días de nevada en invierno y el número de días de nevada en otoño, ninguno de los cuales llega al 0,35 de correlación media.

Tabla 7. Índices de correlación entre los 18 parámetros climáticos y la superficie de las 6 facies de vegetación [1: Roquedales y pedreras. 2: Ventisqueros. 3: Pastizales psicroxerófilos. 4: Pastizales higrófilos. 5: Matorrales abiertos y muy abiertos.

6: Matorrales densos]. En negrita los índices, positivos o negativos, iguales o superiores a 0,70 .

\begin{tabular}{|l|c|c|c|c|c|c|}
\hline & $\mathbf{1}$ & $\mathbf{2}$ & $\mathbf{3}$ & $\mathbf{4}$ & $\mathbf{5}$ & $\mathbf{6}$ \\
\hline T media anual & $\mathbf{- 0 , 8 6}$ & $\mathbf{- 0 , 7 7}$ & $\mathbf{0 , 8 3}$ & $\mathbf{- 0 , 8 0}$ & $\mathbf{- 0 , 7 6}$ & $\mathbf{0 , 8 4}$ \\
\hline T media anual de las máximas & $\mathbf{- 0 , 7 3}$ & $-0,58$ & 0,67 & $-0,64$ & $-0,65$ & 0,68 \\
\hline T media anual de las mínimas & $\mathbf{- 0 , 9 1}$ & $\mathbf{- 0 , 9 4}$ & $\mathbf{0 , 9 3}$ & $\mathbf{- 0 , 9 1}$ & $\mathbf{- 0 , 7 9}$ & $\mathbf{0 , 9 4}$ \\
\hline T media de primavera & $-0,56$ & $-0,33$ & 0,44 & $-0,32$ & $-0,19$ & 0,25 \\
\hline T media de verano & $\mathbf{- 0 , 7 9}$ & $-0,67$ & $\mathbf{0 , 7 6}$ & $\mathbf{- 0 , 7 2}$ & $\mathbf{- 0 , 7 7}$ & $\mathbf{0 , 8 0}$ \\
\hline T media de otoño & $-0,39$ & $-0,50$ & 0,49 & $-0,69$ & $\mathbf{- 0 , 9 6}$ & $\mathbf{0 , 8 9}$ \\
\hline T media de invierno & $\mathbf{- 0 , 9 6}$ & $\mathbf{- 0 , 9 4}$ & $\mathbf{0 , 9 2}$ & $\mathbf{- 0 , 8 9}$ & $-0,58$ & $\mathbf{0 , 8 1}$ \\
\hline Pluviosidad anual & 0,64 & 0,49 & $-0,59$ & 0,63 & $\mathbf{0 , 7 1}$ & $\mathbf{- 0 , 7 0}$ \\
\hline Pluviosidad invernal & 0,65 & 0,50 & $-0,63$ & 0,43 & 0,68 & $-0,60$ \\
\hline Días de precipitación al año & $-0,34$ & $-0,42$ & 0,38 & 0,13 & 0,33 & $-0,16$ \\
\hline Días de nevada al año & $-0,15$ & $-0,36$ & 0,27 & 0,01 & 0,07 & 0,04 \\
\hline Duración anual de la nieve & $\mathbf{0 , 7 3}$ & 0,61 & $-0,65$ & $\mathbf{0 , 8 0}$ & 0,62 & $\mathbf{- 0 , 7 4}$ \\
\hline Días de nevada en otoño & $-0,38$ & $-0,39$ & 0,43 & 0,26 & 0,26 & $-0,19$ \\
\hline Duración de la nieve en otoño & 0,14 & 0,18 & $-0,09$ & $\mathbf{0 , 7 5}$ & 0,48 & $-0,59$ \\
\hline Días de nevada en invierno & 0,29 & 0,12 & $-0,17$ & 0,52 & 0,37 & $-0,41$ \\
\hline Duración de la nieve en invierno & 0,57 & 0,48 & $-0,47$ & $\mathbf{0 , 8 3}$ & 0,47 & $-0,64$ \\
\hline Días de nevada en primavera & $-0,20$ & $-0,44$ & 0,30 & $-0,31$ & $-0,14$ & 0,29 \\
\hline Duración de la nieve en primavera & $\mathbf{0 , 8 0}$ & 0,65 & $\mathbf{- 0 , 7 4}$ & 0,60 & 0,58 & $-0,64$ \\
\hline
\end{tabular}


Todo ello -junto con el grado de analogía de las respectivas líneas de tendencia- indica que las modificaciones observadas en los componentes de la cubierta vegetal de las cuencas de La Condesa y de Valdemartín responden ante todo a cambios termométricos y relativos a la duración de la nieve sobre el suelo, sin que las variaciones en la frecuencia de las precipitaciones y, en concreto, de las nevadas hayan tenido una incidencia apreciable.

Teniendo en cuenta, además de su valor numérico, el carácter positivo o negativo de los índices de correlación y la concordancia directa o inversa de las líneas de tendencia, los procesos de regresión o de progresión de las facies vegetales a lo largo de la segunda mitad del siglo XX, anteriormente definidos y valorados, se relacionan con las variaciones de los caracteres del ambiente climático detectados en este período de la siguiente forma:

La reducción de los ventisqueros se relaciona prioritariamente con el aumento de la temperatura media anual de las mínimas y de la temperatura media de invierno y, en menor medida, con el aumento de la temperatura media anual y de la temperatura media de verano y con la disminución de la duración de la nieve en primavera.

La progresión de los pastizales psicroxerófilos se relaciona prioritariamente con el aumento de la temperatura media anual de las mínimas, de la temperatura media de invierno y de la temperatura media anual y, en menor medida, con la disminución de la persistencia de la nieve en primavera y de la duración anual de la nieve y con el aumento de la temperatura media de verano y de la temperatura media anual de las máximas.

La reducción de los cervunales se relaciona prioritariamente con el aumento de la temperatura media anual de las mínimas, de la temperatura media de invierno y de la temperatura media anual, así como con la disminución de la duración de la nieve en invierno y de la duración anual de la nieve. También se relaciona en menor medida con la disminución de la duración de la nieve en otoño.

La reducción de los matorrales de piorno abiertos y muy abiertos se relaciona muy prioritariamente con el aumento de la temperatura media de otoño y, en menor medida, con el aumento de la temperatura media anual de las mínimas, de la temperatura media anual, de la temperatura media de verano y de temperatura media anual de las máximas y con la disminución de la pluviosidad anual y de la pluviosidad invernal.

La expansión de los matorrales densos de piorno y jabino se relaciona prioritariamente con el aumento de la temperatura media anual de las mínimas, de la temperatura media de otoño, de la temperatura media anual, de la temperatura media de invierno y de la temperatura media de verano $\mathrm{y}$, en menor medida, con el aumento de la temperatura media anual de las máximas y con la disminución de la duración anual de la nieve y de la pluviosidad anual. 


\section{Conclusión}

En las áreas supraforestales culminantes de la Sierra de Guadarrama, de las que son representativas las cuencas de La Condesa y Valdemartín, se han producido modificaciones climáticas significativas a lo largo de la segunda mitad del siglo XX, a las que la cubierta vegetal -constituida por plantas herbáceas y arbustivas adaptadas al frío y, en mayor o menor medida, a la nieve- parece haber sido capaz de responder variando la extensión del área correspondiente a cada una de sus facies principales. Esta variación relacionada fundamentalmente con el aumento de las temperaturas (sobre todo de las invernales), con la reducción de los aportes pluviométricos en forma de nieve en invierno y con el acortamiento del tiempo de permanencia de la cubierta nival sobre el suelo no ha dado lugar a un cambio drástico en el paisaje vegetal, pero sí a un reajuste apreciable del mismo. Como consecuencia de él los matorrales densos han aproximado su superficie a la de los matorrales abiertos y los joragales se han expandido hasta ocupar -tras las formaciones arbustivas anteriores- el tercer lugar en cuanto a extensión, al tiempo que los cervunales higrófilos y los ventisqueros, cuyas áreas eran mayores que la de los pastizales psicroxerófilos a comienzos del período analizado, han sufrido una significativa reducción para ser a finales del mismo las facies menos extensas.

El alto valor de los índices de correlación y la básica analogía de las líneas de tendencia detectadas entre los parámetros climáticos más importantes y las dimensiones de los elementos básicos de la cubierta vegetal -lo que implica que éstas han acompañado a las modificaciones de aquéllos no sólo en su evolución global sino también en sus cambios de ritmo y de sentido durante los cincuenta años analizados- permite afirmar que el reajuste dimensional de las facies antes indicado ha estado condicionado o regido por la evolución del clima. Ello no implica, sin embargo, que éste haya sido el único factor, puesto que existen otros procesos de carácter antrópico, como el abandono de la explotación de la nieve y el cambio cuantitativo y cualitativo de la carga ganadera (cuyo análisis precisa de una investigación específica), capaces de sumarse a él para favorecer la reducción de los ventisqueros o la progresión de los piornal-jabinales densos.

Tampoco permite asegurar que las modificaciones del ambiente climático sean definitivas o que su sentido deba mantenerse, ni que la distribución de los componentes de la cubierta vegetal de las áreas supraforestales de la sierra de Guadarrama no pueda ya modificarse o vaya seguir de forma indefinida las mismas pautas. La observación de las series de datos meteorológicos de la estación de Puerto de Navacerrada desde 1941 hasta el presente pone de relieve que las variaciones del clima registradas en la segunda mitad del siglo XX no difieren de las registradas con anterioridad y que las tendencias de cambio han invertido su sentido conforme a unos ciclos dentro de cuyas dimensiones temporales aún se encuentran las registradas en el período de referencia (Servicio Meteorológico Nacional, 1976; Instituto Nacional de Meteorología, 1995 y 2002). No es posible por lo tanto descartar que a medio plazo pueda producirse la reversión de algunos de los procesos que en el pasado reciente han afectado a la cubierta vegetal de las cuencas de La Condesa y Valdemartín. 


\section{Agradecimientos}

Este trabajo se ha realizado con el apoyo del Proyecto de investigación CAM 07/0055/2002 (“Cobertura nival, colonización vegetal y cambio climático en el Parque Natural de Peñalara”), financiado por la Comunidad de Madrid.

\section{Referencias bibliográficas}

Alarcón López S., Martínez Martínez, M.T. y Martínez Molina, I. (1984). Climatología de Puerto de Navacerrada, Madrid, Instituto Nacional de Meteorología.

Corella SuÁrez, P. (1988). El comercio de la nieve y del hielo en la provincia de Madrid. En Establecimientos tradicionales madrileños. Cuaderno VIII, Periferia de Madrid y pueblos de la Comunidad, Madrid, Cámara de Comercio e Industria (pp. 229-240).

Fernández GonzÁlez, F. (1991). La vegetación del valle del Paular (Sierra de Guadarrama, Madrid), Lazaroa, 12: 153-272.

Gavilán, R., Fernández González, F. y Blasic, C. (1998). Climatic classification and ordination of the Spanish Sistema Central: relationships with potential vegetation, Plant Ecology, 139: 1-11.

Instituto Nacional de Meteorología (1995). Valores normales y estadísticos de estaciones principales (1961-1990). Observatorio de Madrid "Puerto de Nacavacerrada”, Madrid, INM.

Instituto Nacional de Meteorología (2002). Observatorio Meteorológico de Madrid 'Puerto de Navacerrada'. En Valores normales y estadísticos de los observatorios meteorológicos principales (1971-2000). Volumen 4. Madrid, Castilla La Mancha y Extremadura, Madrid, INM (pp. 67-86).

Mas Hernández, R. (1998). El territorio. En Martínez de Pisón, E (dir.), Madrid y la Sierra de Guadarrama, Madrid, Museo Municipal (pp. 37-77).

Palacios, D., Andrés, N. y Luengo, E. (2003). Distribution and effectiveness of nivation in mediterranean mountains: Peñalara (Spain), Geomorphology, 54: 157-178.

Palacios, D. y García SÁnchez-Colomer, M. (1997). The influence of nival erosion on the distribution of high mountain vegetation to snow cover: Peñalara, Spain, Catena, 30: 1-40.

Rivas Martínez, S., Belmonte, D., Cantó, P., Fernández González, F., Fuente, V., Moreno, J.M., SÁnchez Mata, D. Ygercía Sancho, L. (1987). Piornales, enebrales y pinares oromediterráneos (Pino-Cytision oromediterranei) en el Sistema Central, Lazaroa, 7: 13-124. 
Rivas-Martínez, S., Cantó, P., Fernández González, F., Navarro, C. y Sánchez Mata, D. (1989). Sinopsis de la vegetación saxícola del Sistema central, Madrid, Facultad de Farmacia (Universidad Complutense).

Rivas-Martínez, S., Cantó, P., Fernández González, F., Molina, J.A., Pizarro, J.M. y SÁnchez Mata, D. (1999). Sinopsis of the Sierra de Guadarrama vegetation, Itinera Geobotánica, 13: 189-206.

SANZ, C. (1979). El mosaico de geofacies supraforestales en la zona más elevada de la Sierra de Guadarrama. En VI Coloquio de Geografía, Palma de Mallorca, Asociación de Geógrafos Españoles (pp. 243-248).

Sanz C. (1988). El relieve del Guadarrama oriental, Madrid, Comunidad de Madrid (Consejería de Política Territorial).

Servicio Meteorológico Nacional (1976). Relación de valores normales correspondientes a Observatorios Principales con datos del período 1931-60, Madrid, SMN (policop.).

Valenzuela Rubio, M. (1977). Urbanización y crisis rural en la Sierra de Madrid, Madrid, Instituto de Estudios de Administración Local. 
